\title{
Effect of Different Commercial Fertilizers, Harvest Date, and Storage Time on Two Organically Grown Blackberry Cultivars: Physicochemical Properties, Antioxidant Properties, and Sugar Profiles
}

\author{
George Cavender (D), ${ }^{1}$ Mingyang Liu, ${ }^{2}$ Javier Fernandez-Salvador, ${ }^{3}$ Deborah Hobbs, \\ Bernadine Strik, ${ }^{3}$ Balz Frei, ${ }^{4}$ and Yanyun $\mathrm{Zhao}^{2}$ \\ ${ }^{1}$ University of Georgia, Department of Food Science and Technology, 122 Food Science Building, Athens, GA 30602-2610, USA \\ ${ }^{2}$ Oregon State University, Department of Food Science and Technology, 100 Wiegand Hall, Corvallis, OR 97331, USA \\ ${ }^{3}$ Oregon State University, Department of Horticulture, 4017 Agriculture and Life Sciences Building, Corvallis, OR 97331, USA \\ ${ }^{4}$ The Linus Pauling Institute, 307 Linus Pauling Science Center, Corvallis, OR 97331, USA
}

Correspondence should be addressed to George Cavender; cavender@uga.edu

Received 7 January 2019; Revised 16 April 2019; Accepted 8 May 2019; Published 1 July 2019

Guest Editor: Maria del Mar Contreras Gamez

Copyright (c) 2019 George Cavender et al. This is an open access article distributed under the Creative Commons Attribution License, which permits unrestricted use, distribution, and reproduction in any medium, provided the original work is properly cited.

\begin{abstract}
Despite increased consumer interest in organic produce, little is known about how different organic production methods affect both the traditional measures of quality and the naturally occurring health promoting (bioactive) compounds of food. In this study, "Obsidian" and "Triple Crown" blackberries (both Rubus hybrids) were cultivated organically and fertilized with either soy meal, fish emulsion/hydrolysate blend, or processed poultry litter fertilizers at a fixed rate. Fruits were hand-harvested three times during their peak production period and stored at $4^{\circ} \mathrm{C}$ and $85 \% \mathrm{RH}$ for up to $12 \mathrm{~d}$. Fertilizer effects on the physicochemical properties were minor, while harvest period had a stronger effect, though that trend varied by year. Antioxidant and sugar profile data revealed an interesting pattern: "Obsidian" had ORAC and lower sugar than "Triple Crown" at harvest and also had greater differentiation due to fertilizer treatments. Fertilizer effects differed based on harvest date and cultivar, with late harvest fruit fertilized with fish emulsion fertilizer showing higher TPC and ORAC than other fertilizer treatments, while the early and middle harvest fruit showed similar or greater responses to soy meal-based fertilizer. Time of harvest and length of storage also affected the antioxidant properties and sugar profiles in different ways depending on fruit cultivar, again with the "Obsidian" fruit showing greater variability in general. This study demonstrated that the two cultivars of organically grown blackberry fruit have different physicochemical and antioxidant properties, thus potentially different shelf lives in the fresh market.
\end{abstract}

\section{Introduction}

Consumer interest in organic produce has resulted in the rapid growth of organic agriculture in the US, with total acreage of organic crops increasing 253\% between 2000 and 2011, and the previous year data are available from USDA [1]. One of the major reasons for consumer choosing organic produce is the belief that the products are "healthier for me and my children" [2]. Meanwhile, public health experts are recommending increased consumption of fruits because they are rich in natural antioxidants that have been linked to reduced risk of various health maladies, including cancer, coronary heart disease, metabolic disorders, and inflammatory responses [3-8].

Conventional farming has been able to keep up with increased demand for blackberries through new cultivars and improved agricultural practices, and by $2005,4,818$ ha of land were able to produce 31,840 metric tons of blackberries [9]. Though many of the improved practices should translate well into organic production systems, there are some 
limitations. For example, one of the most important factors that can affect plant productivity is the fertilizer regimen used, and while many studies have been undertaken to determine the ideal amounts and application times of conventional fertilizer in order to optimize blackberry production [10], the published guidelines and recommendations tend to focus solely on the rates of nitrogen application, making little or no distinction in the nitrogen source, aside from the general caveat that nitrate forms are better than amide forms [10-12].

This lack of focus on the type of nitrogen source is problematic for organic growers; while conventional/ synthetic fertilizers are composed of a handful of industrial chemical compounds, organic fertilizers are derived from plant/animal wastes and as such are much more complex. Even if it were possible to extrapolate the guidelines for conventional fertilizers to organic ones, it is entirely possible that the plants will respond differently as studies which have compared conventional and organic production methods in various crops have shown marked differences in performance and fruit/vegetable quality [10, 13-17]. Even among different types of organic fertilizer, great variability was found in horticultural measures of performance, such as yield and nitrogen uptake $[18,19]$. Further, it is unknown how the different organic fertilizer sources can affect the overall fruit quality, thus a question that needs to be answered, particularly given that Bulluck et al. [20] showed that different organic fertilizer sources not only affect crop yield but also modify the physical, chemical, and microbial properties of the soil itself and in turn the quality of fruit [21-24].

Being living systems, fruiting plants also show variability during the course of the growing season, and this variability can greatly affect the quality and health properties of the fruit, as has been shown in several studies. Basiouny [25] found that anthocyanin content and shelf life decreased in later harvest blackberries, and Thompson et al. [26] noted a decline in total soluble solids, total phenolic content, anthocyanin content, and $\mathrm{pH}$ as harvest season progressed. While these studies dealt with conventionally grown (CG) berries, more recent studies involving organically produced blackberries have shown that harvest time has a marked effect on total yield, average berry weight, and total soluble solids [24, 27].

Given the focus on perceived health benefits of organically grown produce, it is essential to quantify the bioactive compounds and antioxidant potential of organic blackberry fruit. The former allows the characterization of known compounds which may have been linked to particular health benefits, while the latter attempts to give an overall measure of how well all of the compounds scavenge specific types of free radicals compared with a set standard. Further measurements of antioxidant potential will vary based on the free radical and comparative standard used in the assay, making comparison between different methods difficult. These benefits and drawbacks lead most researchers to perform one or more assays of each type in an attempt to get a better overall grasp of the antioxidant properties, as well as allow for more avenues of comparison with previous studies.
Most antioxidant studies involving blackberries have focused on total phenolic compounds and anthocyanins, as blackberries are well known to be high in both, and also often included one or two measures of antioxidant activity $[3,4,28-30]$. Despite the potential effect of fertilizer source on the antioxidant properties of blackberries, there have been no published studies on the subject.

This study aimed to examine the effect of differing organic nitrogen sources and harvest periods on the physicochemical and antioxidant properties of two different organically grown blackberry cultivars at the time of harvest and during refrigerated storage. Specifically, the rates of decay and leakage, berry firmness, sugar profile, total phenolic content, total monomeric anthocyanins, and the overall antioxidant potential were measured and compared using three different methods were measured and compared. It is important to note that this study did not compare organically and conventionally produced fruit, primarily based on the consideration that in order to properly compare organic and conventional fruit, the plants must be grown in the same planting area with replicated treatments. This is extremely difficult if not impossible, as the "organic" could never be certified organic due to the close proximity of the conventional plots and the size of the required buffer zones.

\section{Materials and Methods}

2.1. Materials. All chemical reagents were analytical grade, except for the ultrapure $(<18.2 \mathrm{M} \Omega \mathrm{cm})$ water used as a mobile phase in HPLC analysis of sugar profile, which was prepared in situ using a Millipore filtration system (Millipore Corp., Bedford, MA USA).

Two blackberry cultivars, "Obsidian" and "Triple Crown," were evaluated in this study, chosen for their suitability for the Pacific Northwest fresh market. Specifically, "Obsidian" berries have an early harvest season (midJune to mid-July), while "Triple Crown" has a later harvest season (mid-August to early September). All berries used in this study were grown on a certified organic farm (Riverbend Organic Farms, Jefferson, OR, USA) in eighteen separate plots (9 plots for each cultivar). Complete details of the growing conditions were described in the recent publication of Fernandez-Salvador et al. [27]. Briefly, all plots were grown using the same management system (e.g., irrigation, pest control scheme, and weed management technique) and were fertilized with one of the three commercial organic fertilizers: processed poultry litter (PPL-"Nutri Rich 4-3-3 Ca 7\%," Stutzman Farms, Canby, OR USA), soy meal (SM"Phyta-grow leafy green special," California Organic Fertilizers Inc., Fresno, CA USA), or a blend of fish emulsion and fish hydrolysate (FE-“True 402," True Organic Products Inc., Helm, CA USA). All fertilizers were applied at the recommended nitrogen rate $(56 \mathrm{~kg} \mathrm{~N} / \mathrm{he})$, and distribution of fertilizer treatments was randomized within blocks of three plots.

Berries were hand-harvested three times during the 2012 and 2013 growing seasons (July 6-17 and June 24 to July 9, for "Obsidian" in 2012 and 2013, respectively; August 10-24 and August 1-15 for "Triple Crown" in 2012 and 2013, 
respectively) for a given cultivar at approximately one week interval and named as "Early Harvest," "Middle Harvest," and "Late Harvest," respectively. Note that depending on the weather conditions (temperature and UV index), the exact harvest date varied year by year. Approximately 16 berries were placed into each hinged polyethylene terephthalate (PETE) clamshell container (Pactiv, LLC, Lake Forest, IL, USA). Individual containers were placed into open-topped cardboard boxes, stored at $4 \pm 1^{\circ} \mathrm{C}$ and $85 \% \mathrm{RH}$ and sampled at days $0,2,4$, and 6 and $0,2,5,8$, and 10 for "Obsidian" in 2012 and 2013, respectively, and at days $0,4,10$, and $12( \pm 1)$ and $0,4,8,10$, and 12 for "Triple Crown" in 2012 and 2013, respectively, with sampling discontinued when more than half of the berries in a given container were found to be decayed. On each sampling day, one randomly determined container from each of the 9 plots was removed from storage.

2.2. Fruit Decay and Leakage. Decay and leakage of fruit were evaluated following the procedures described by Civello et al. [31] with some modifications. Briefly, individual fruits were gently taken out of the clamshell containers and inspected visually for mold growth and/or extensive damage (defined as having $<3 \mathrm{ruptured} /$ crushed contiguous drupelets or $<5$ ruptured/crushed drupelets overall), either of which rendered a berry "decayed." Nondecayed fruits were tested for leakage by transferring them to a standard "letter size" $(215.9 \mathrm{~mm} \times 279.4 \mathrm{~mm})$ sheet of white printer paper and gently rolled, so that all berry surfaces had been exposed to the paper. Juice stains on the paper rendered a fruit "leaking." Decay rate was calculated as the percentage of berries in a container which were decayed, while leakage was calculated as the percentage of nondecayed berries in a container which were leaking.

2.3. pH and Titratable Acidity. $\mathrm{pH}$ and titratable acidity (TA) were determined using the methods from Fisk et al. [32]. Two individual fruits from each clamshell container were used for describing measurements. The fruit was mixed with 9 times of fruit weight of distill water and blended for $1 \mathrm{~min}$ using a 12-speed homogenizer (Osterizer, Jarden Corp., Mexico). The mixture was filtered through qualitative filter paper to remove insoluble material. The filtrate was assayed for $\mathrm{pH}$ using a $\mathrm{pH}$ meter (Corning 125, Corning Science Products, Medfield, MA, USA), TA was determined by titration to an endpoint of $\mathrm{pH} 8.2$ with a standardized $0.1 \mathrm{~N}$ aqueous $\mathrm{NaOH}$ solution, and values were calculated based on the assumption of malic acid as the predominant acid.

2.4. Fruit Firmness. Five nondecayed berries from each clamshell container were individually measured on each sampling date for firmness using methodology originally developed by Joo et al. [33] with modification to better approximate the conditions of the nondestructive subjective manual test commonly used by growers [34]. Briefly, berries were placed on their side, and the force (in $\mathrm{N}$ ) required to compress the berry $5 \%$ of its total thickness was measured using a texture analyzer (Model TA-XT2, Texture Technologies Corp. Scarsdale, NY, USA) fitted with a $25 \mathrm{~kg}$ load cell and a $50 \mathrm{~mm}$ cylindrical probe.

2.5. Fruit Extraction for Antioxidant Assays. Four berries were taken from each clamshell container and combined according to treatment group, giving 12 berry samples from each, and rapidly frozen by immersion in liquid nitrogen. Frozen samples were then pulverized under liquid nitrogen using a one-liter blender (Waring Laboratory Science, Torrington, CT, USA) which had been fitted with a specialized lid to allow for pressure release while preventing sample loss.

Samples of pulverized berry powder $(15 \mathrm{~g})$ were subjected to a modified ultrasound assisted sequential extraction procedure developed in our laboratory [35]. Briefly, a given sample was extracted first using acidified acetone $(0.1 \mathrm{~mL} / \mathrm{L}$ $\mathrm{HCl}$ ), then twice with a 3:7 of water:acidified acetone solution, with each extraction involving a fixed time ultrasound treatment $(90,300$, and $300 \mathrm{~s}$, respectively). After centrifuging, supernatants were decanted and pooled together for partitioning with $150 \mathrm{~mL}$ of chloroform, vortexing thoroughly, and centrifuging to separate the two phases for removing any lipophilic components. The aqueous phase was then decanted and evaporated to remove residual organic solvents using a rotary evaporator (Rotovap, Brinkmann Instruments, Westbury, NY, USA). Extract volume was standardized to $150 \mathrm{~mL}$ using deionized (DI) water, and $1.5 \mathrm{~mL}$ aliquots of the standardized solutions were stored at $-80^{\circ} \mathrm{C}$ until the time of assay.

2.6. Juice Extraction for Sugar Profiling. A modified procedure from Qian [36] was used to prepare aqueous berry extracts. Briefly, $\sim 35 \mathrm{~g}$ of the pulverized berry powder not used for the antioxidant assays were mixed with DI water equal to $1 / 2$ the mass of the sample in a glass jar. Jars were fitted with lids and immersed in a boiling water bath $\left(100^{\circ} \mathrm{C}\right)$ for $20 \mathrm{~min}$ to inactivate enzymes. The resultant juice/slurry was centrifuged to remove solids and decanted into clean polypropylene bottles for storage at $-25^{\circ} \mathrm{C}$ until the time of assay. Extracts were prepared from berries harvested during the 2012 season only in order to avoid the variation inherent to the first fruiting of blackberries.

2.7. Analysis of Total Phenolic Content (TPC). TPC was determined using the Folin-Ciocalteu colorimetric method, as described by Singleton et al. [37]. Briefly, aqueous extracts were diluted until their absorbance value was less than 1.2 , and $0.5 \mathrm{~mL}$ aliquots of this diluted sample were added to tubes containing $7.5 \mathrm{~mL}$ of DI water and $0.5 \mathrm{~mL}$ of FolinCiocalteu reagent. After vortexing to mix, solutions were allowed to react for $10 \mathrm{~min}$ before the addition of $3 \mathrm{~mL}$ of $20 \%$ sodium carbonate solution. The resultant mixture was vortexed and then placed into a $40^{\circ} \mathrm{C}$ water bath for $20 \mathrm{~min}$. Following the heat treatment, samples were plunged into a $0^{\circ} \mathrm{C}$ ice/water bath until they were at or below room temperature. Absorbance of the samples at $765 \mathrm{~nm}$ was 
measured using a spectrophotometer (Model UV160U, Shimadzu Corporation, Kyoto, Japan). These values were used to calculate gallic acid equivalents based upon the equation of a standard curve prepared the same day using solutions of gallic acid (0, 150, 200, and $250 \mathrm{ppm})$. Assays were performed in triplicate, and values were reported as $\mathrm{mg}$ gallic acid equivalents (GAE)/g fresh weight (FW).

2.8. Analysis of Radical Scavenging Activity (RSA). The refined colorimetric assay method relying on the reduction of the stable free radical 2,2-diphenyl-1-picryhydrazyl (DPPH) [38] was used to determine RSA. Briefly, $1.5 \mathrm{~mL}$ of freshly prepared DPPH solution in methanol $(0.09 \mathrm{mg} / \mathrm{mL})$ was added to disposable cuvettes containing $0.75 \mathrm{~mL}$ of diluted fruit extract, mixed, and allowed to react at room temperature for $5 \mathrm{~min}$. Absorbance at $517 \mathrm{~nm}$ was measured and used to calculate ascorbic acid equivalents (AAE) based upon the equation of a standard curve prepared the same day using ascorbic acid solutions (0, 100, 200, 300, and 400 ppm).
Assays were performed in triplicate, and values were reported as mg AAE/g FW.

2.9. Analysis of Total Monomeric Anthocyanins (TMA). The spectrophotometric method based upon $\mathrm{pH}$-induced changes in absorbance (Giusti and Wrolstad [39]) was used to assay TMA. Briefly, for each sample, aliquots of extract were placed into two disposable cuvettes, diluted with either a standardized sodium acetate buffer $(\mathrm{pH} 4.5)$ or a standardized potassium chloride buffer ( $\mathrm{pH} 1.0)$, and allowed to equilibrate for at least $15 \mathrm{~min}$ at room temperature. Optical absorbance was measured at both $510 \mathrm{~nm}$ and $700 \mathrm{~nm}$, with the former value being selected based upon the predominant anthocyanin in blackberries, cyanidin-3-glucoside [28, 29]. Absorbance values were then used to calculate concentration of monomeric anthocyanins (expressed as mg TMA/g FW) in the fruit using the Beer-Lambert-Bouguer law according to the following equation:

$$
\operatorname{TMA}\left(\frac{\mathrm{mg}}{\mathrm{gFW}}\right)=\frac{\left[\left(A_{510 \mathrm{~nm}}-A_{700 \mathrm{~nm}}\right)_{\mathrm{pH} \mathrm{1.0}}-\left(A_{510 \mathrm{~nm}}-A_{700 \mathrm{~nm}}\right)_{\mathrm{pH} 4.5}\right] \times 449.2(\mathrm{~g} / \mathrm{mol}) \times D F \times 1000(\mathrm{mg} / \mathrm{g})}{26900(\mathrm{~L} /(\mathrm{cm} \cdot \mathrm{mol})) \times 1 \mathrm{~cm}} \times \frac{1 \mathrm{~L}}{100 \mathrm{~g} \mathrm{FW}}
$$

where DF is the dilution factor and each extract was assayed three times.

2.10. Oxygen Radical Absorbance Capacity (ORAC). ORAC was measured using the fluorescent method described by Cao et al. [40] which had been adapted for use in a 96-well microplate fluorometer (SpectraMax Gemini XS, Molecular Devices, Foster City, CA, USA). Briefly, three $30 \mu \mathrm{L}$ aliquots of each extract (diluted as necessary) were dispensed into the wells of a prewarmed microtiter plate along with $200 \mu \mathrm{L}$ of a prewarmed $\beta$-phycoerythrin solution $(6.65 \mu \mathrm{g} / \mathrm{ml}$ in phosphate-buffered saline, $\mathrm{pH} 7.4)$. Microtiter plates were incubated at $37^{\circ} \mathrm{C}$ for $1 \mathrm{~h}$, after which $70 \mu \mathrm{L}$ of $2,2^{\prime}$-azobis(2-amidinopropane) dihydrochloride (AAPH) was added to initiate the reaction. Fluorescence of $\beta$-phycoerythrin was induced by excitation at $485 \mathrm{~nm}$ and was measured at $585 \mathrm{~nm}$ every $2 \mathrm{~min}$ for $2 \mathrm{~h}$. Proprietary software (SoftMax Pro 5.4.5, Molecular Devices, LLC, USA) was used to calculate the antioxidant capacity based upon positive changes to the area under the curve as compared to curves generated using a series of standardized Trolox solutions $(0,10,20$, or $40 \mu \mathrm{mol} / \mathrm{L})$. Results were expressed as $\mu$ mol Trolox equivalent (TE)/g FW.

2.11. Ferric Reducing Antioxidant Power (FRAP). FRAP was assayed using the automated colorimetric method developed by Benzie and Strain [41]. Duplicate aliquots of $40 \mu \mathrm{L}$ were taken from each extract and dispensed into the wells of a prewarmed microtiter plate along with $300 \mu \mathrm{L}$ of prewarmed FRAP reagent (a mixture of $83 \% 300 \mathrm{mmol} / \mathrm{L}$ acetate buffer, $3.5 \% 10 \mathrm{mmol} / \mathrm{L}$ tri(2-pyridyl)-s-triazine, and 3.5\%
$20 \mathrm{mmol} / \mathrm{L}$ iron (III) chloride). Plates were incubated at $37^{\circ} \mathrm{C}$ for $15 \mathrm{~min}$ and then measured for absorbance at $550 \mathrm{~nm}$ using a microplate absorbance reader (SpectraMax 190, Molecular Devices, Foster City, CA). Proprietary software (SoftMax Pro 5.4.5, Molecular Devices, LLC, USA) was used to calculate antioxidant power from the measured absorbance values based upon a standard curve generated from a series of standardized Trolox solutions $(0,62.5,125,250$, or $500 \mathrm{mmol} / \mathrm{L}$ Trolox). Values were reported as $\mu \mathrm{mol}$ Trolox equivalent (TE)/g FW.

2.12. Analysis of Sugar Profile. A high-pressure liquid chromatography (HPLC) system, consisting of a quaternary pump, solvent degasser, autosampler, column heater, and refractive index detector (Series 1200, Agilent Technologies, Santa Clara, CA, USA), was fitted with a $300 \mathrm{~mm} \times 7 \mathrm{~mm}$ ligand exchange column (particle size $8 \mu \mathrm{m}$ ), and an appropriate guard column (Hi-PLex $\mathrm{pB}$, Varian, Inc., Palo Alto, CA, USA) was used to determine the sugar profile of the fruit according to the method of Cavender et al. [42]. All samples were assayed in triplicate, and the concentrations of the three major sugars (fructose, sucrose, and glucose) were calculated based upon standard curves constructed using a series of pure sugar solutions $(0.9375,1.875,3.75$, and $7.5 \mathrm{~g} /$ $100 \mathrm{~mL}$ of each).

2.13. Experimental Design and Statistical Analysis. A completely randomized design was employed in this study with the principle effects being fertilizer treatment and harvest date. Data were analyzed for statistical significance via multiway analysis of variance (ANOVA) with least significant 
difference (LSD) post hoc testing as appropriate, using statistical software (SAS v9.2, the SAS Institute, Cary, NC, USA). Results were considered to be different if $p$ value $<0.05$.

\section{Results and Discussion}

3.1. Fruit Decay and Leakage. For both decay and leakage, fertilizer types had no significant influence on the measures, but harvest date did. Figures 1 and 2 present the mean measures across all three fertilizer treatments for the 2012 and 2013 harvest, respectively. Decay rates for the two cultivars ranged $5.56-54.86 \%$ in 2012 and $0.74-46.89 \%$ in 2013, with "Triple Crown" having higher decay rate in 2012 and "Obsidian" having higher decay rate in 2013; though in the former case, it should be noted that the "Triple Crown" storage time was twice as long as the "Obsidian." Examining the effect of storage time on decay showed decay rates tending to increase with prolonged storage, which was fairly predictable, given that the decay of blackberries is usually caused by fungal growth, and Botrytis cinerea, the primary fungal disease of ripe blackberry fruit, can continuously grow at low temperatures [33, 43].

Leakage rates remained more flat, ranging $27.08-72.34 \%$ in 2012 , and $40.77-89.63 \%$ in 2013 , with the data for a given storage time/harvest date showing great variability, and "Triple Crown" tending to have slightly higher leakage rates in both years. Harvest date also contributed to the differences in the two measures, though its effect varied greatly between cultivars and harvest years. This variability can be explained by differences in weather conditions at the time of fruit harvest which can directly impact fruit ripeness, mold growth, and some other physicochemical properties. In particular, rain during or immediately prior to harvest can result in significant fruit decay due to favorable mold growth conditions, and high temperature and high UV index may result in advanced ripening which leads to loss of firmness and greater fruit leakage $[44,45]$.

"Obsidian" and "Triple Crown" have about one month harvest period in June-July and August-September, respectively [46]. In order to maintain the uniform quality of fruit for fresh market, the growers usually picked up fruit at 2 3 different times during the harvest season [32]. Based on the results obtained in this study, according to USDA standards of grades on blackberries (United States Department of Agriculture (1928)), organically grown "Obsidian" berries are marketable for roughly $2 \mathrm{~d}$, while "Triple Crown" berries remain so for about $4 \mathrm{~d}$. These values are reasonable compared with other commercial varieties, as Perkins-Veazie et al. [45] reported decay rate exceeded $35 \%$ after 7 days in the "Cheyenne" and "Shawnee" cultivars. However, later work by the same group highlights the natural year-to-year variability of such measures, showing decay rates less than $12 \%$ decay after $7 \mathrm{~d}$ of refrigerated storage for "Shawnee" [47].

3.2. $\mathrm{pH}$ and Titratable Acidity of Fruit. Overall, the $\mathrm{pH}$ values of both cultivars were within the range reported for eleven conventionally grown blackberry cultivars [48]. Still, within these values, there was variability based on harvest year, cultivar, harvest time, and storage. In 2012, while no significant difference in $\mathrm{pH}$ between the two cultivars was observed and no significant change was seen due to storage, TA values showed more variation. Specifically, in the initial (day 0) TA values, "Obsidian" had higher levels than "Triple Crown," and the TA values of early and late harvest fruit of both cultivars decreased during storage. Further, for "Obsidian," harvest date affected both TA and $\mathrm{pH}$ in 2012, with early harvest fruits showing significantly lower $\mathrm{pH}$ and higher TA than middle harvest fruits. "Triple Crown" showed higher initial $\mathrm{pH}$ in the late harvest fruits compared with the early harvest, but these differences vanished during storage, while the $\mathrm{pH}$ of early and middle harvest fruits increased $5.72 \%$ and $6.85 \%$, respectively, during the $12 \mathrm{~d}$ of storage. Similar trends were seen in the TA values for "Triple Crown" for that year.

The fruit from the 2013 harvest followed a different pattern of trends, with "Obsidian" having higher initial (day 0) pH and TA than "Triple Crown." Unlike the 2012 harvest year, in 2013, "Obsidian" berries from the three harvests showed no significant difference in either initial $\mathrm{pH}$ or TA, but after $10 \mathrm{~d}$ of storage, TA of early harvest "Obsidian" fruits was slightly higher than those of the late harvest $(1.30 \%$ vs. $1.06 \%)$. Within a given harvest, storage time had a limited effect as well, with $\mathrm{pH}$ of early harvest fruit decreasing and TA increasing after $10 \mathrm{~d}$ of storage, and the late harvest fruit undergoing a slight $(\sim 2.97 \%)$ increase in TA during the first $5 \mathrm{~d}$ of storage, but not thereafter. TA of the middle harvest fruit also decreased significantly at $10 \mathrm{~d}$ of storage, going from 0.96 to $0.67 \%$. For the "Triple Crown" fruit, the initial $\mathrm{pH}$ of the middle harvest was significantly higher than that early and late harvest one at the harvest, but the late harvest fruit showed significantly higher initial TA than the fruit from other two harvest dates. Storage also had some effects, with the late and middle harvest fruit undergoing significant increases ( $16 \%$ and $17.1 \%$, respectively) over the $12 \mathrm{~d}$ of storage, which was also accompanied by a more profound decrease in TA (29.38\% and $23.02 \%$, respectively).

As it is well known that fruit metabolism consumes starch and acid during postharvest storage, leading to increases in $\mathrm{pH}$ and decreases in TA $[49,50]$, our results are hardly surprising. Both "Obsidian" and "Triple Crown" cultivars showed decrease in TA during storage, which was also reported in other conventionally grown blackberry cultivars [33, 47]. Perkins-Veazie et al. [45] reported that TA decreases $60 \%$ between mottled and shiny black stage and decreases $40 \%$ between shiny and dull black stage. We might conclude that the high TA value in our study for the early harvest fruit is due to the less ripe of the fruit that the acids inside the fruit have not been converted to sugar compounds yet. Woods et al. [51] reported $\mathrm{pH}$ increase of conventionally grown "Triple Crown" and other cultivars during storage, probably owning to the binding of pectin from the fruit cell wall to polyphenols [52].

3.3. Fruit Firmness. No significant differences in firmness were seen between berries grown with different fertilizer 

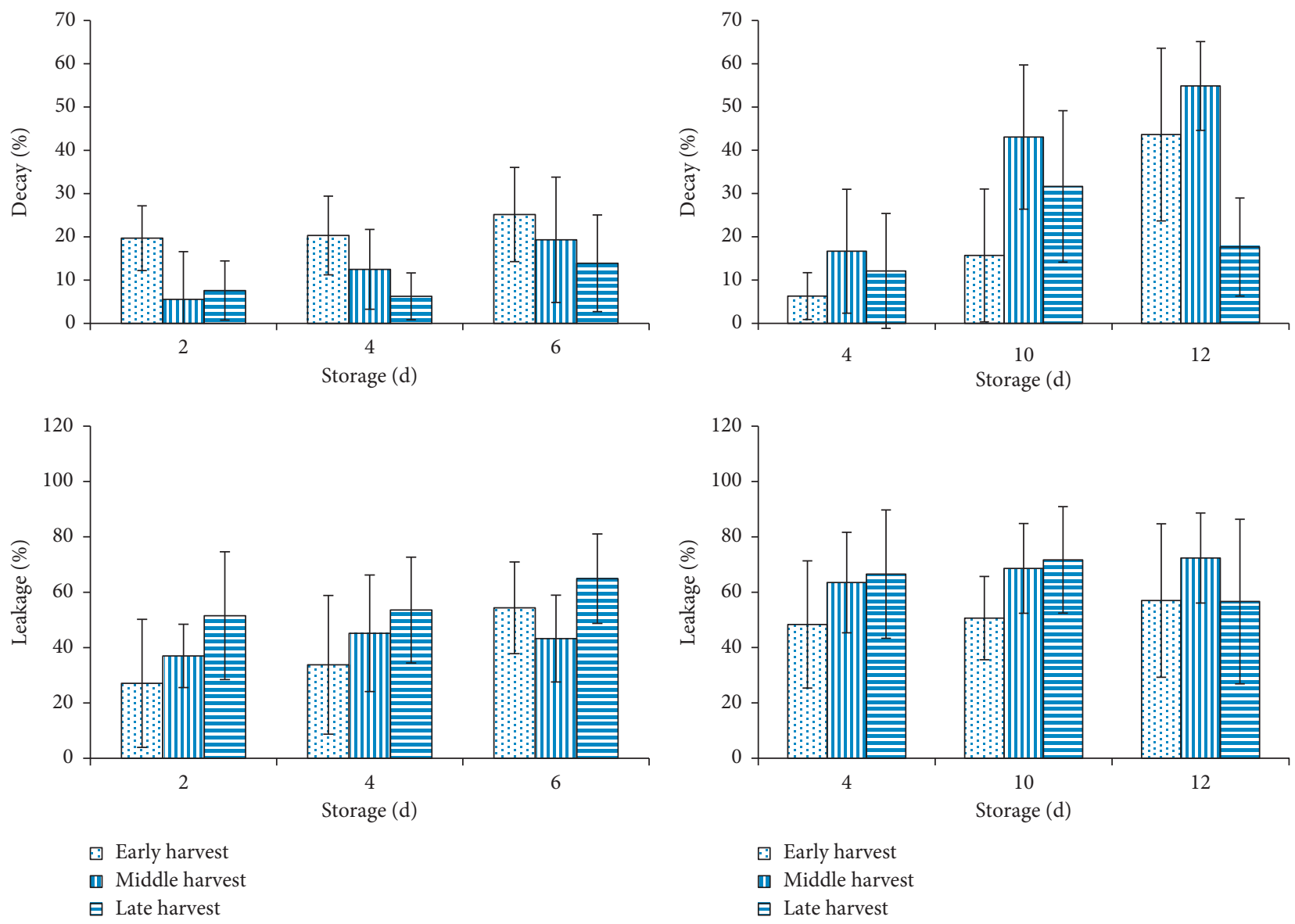

(a)

(b)

FIGURE 1: Effects of harvest date and refrigerated storage on the decay and leakage rate of two blackberry cultivars: "Obsidian" (a) and "Triple Crown" (b), 2012 harvest.

types, but differences were seen among the different harvest dates in both years. Figure 3 presents the mean values across all three fertilizer types. In general, "Obsidian" fruits were firmer than "Triple crown" during both harvest years, with initial values of the former ranging $1.28-2.23 \mathrm{~N}$ in 2012 and $0.84-0.99 \mathrm{~N}$ in 2013 , while the initial values of the latter ranged $1.06-1.90 \mathrm{~N}$ and $0.65-0.87 \mathrm{~N}$ in the same years. In general, these values were consistent with those reported in previous works on conventional berries [33, 53, 54]. Further, the differences between the two were not surprising, given that trailing cultivars like "Obsidian" typically produce firmer fruit than semierect cultivars like "Triple Crown" [46].

Comparing harvest years, in both cultivars, the fruits from the 2012 harvest were firmer than those harvested in 2013, and the effect of storage showed variation among the two cultivars and harvest years, with most experiencing the expected stability or decline during storage, but some, specifically early and middle harvest "Obsidian," seeing increases in firmness by $4 \mathrm{~d}$ of storage. While this effect was present in both harvest years, it was more pronounced (but also had greater variation) in 2012. These variations in firmness were likely due to the variance of ripeness between individual berries, as the less ripe fruit is typically firmer than that of the ripe or overripe fruit [45].
Fruit softening, one of the more important factors of postharvest deterioration, involves a series of physiological and biochemical changes resulting in cell wall hydrolysis and pectin degradation $[49,5556]$. While these changes tend to result in softer fruit, it is possible that enzymatic transformations of cell wall pectin and the bonding of calcium to pectic acid polymers could potentially lead to some amount of fruit hardening during storage [53]. While this might explain the increase in hardness observed in the 2012 early and middle harvests of the "Obsidian" fruit, which increased reached peak firmness after 2-4 d of storage, it also may have a simpler explanation, namely, that berries become more fragile as they ripen, increasing their risk of microbial spoilage. Thus, the berries which were the softest at harvest may have become decayed by day 2 or day 4 , excluding them from firmness testing.

The variations are seen in the 2012 "Triple Crown" harvest, specifically the lack of significant change in firmness for the middle harvest fruit and greater firmness in the late harvest fruit compared with the early and middle harvest is likely the result of environmental/weather concerns, as the fruits developed during a period of elevated temperature and UV index. These conditions likely lead to physical damage to the fruits. The effects of the environment appear again 

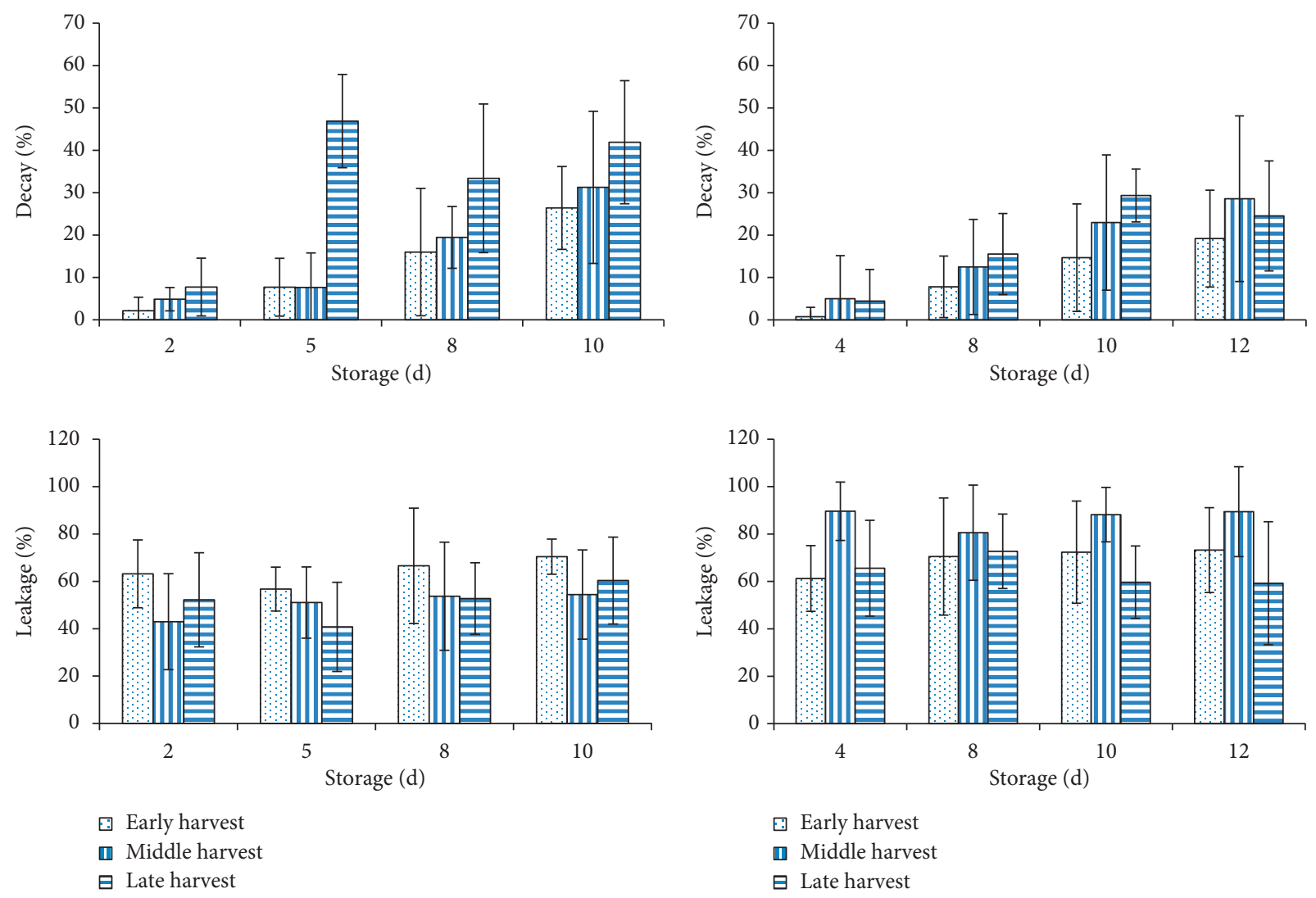

(a)

(b)

FIGURE 2: Effects of harvest date and refrigerated storage on the decay and leakage rate of two blackberry cultivars: "Obsidian" (a) and "Triple Crown" (b), 2013 harvest.

during the 2013 harvest, where a period of elevated temperatures likely resulted in the lower firmness levels seen in the late harvest "Obsidian" fruit, compared with the early and middle harvest.

Unlike the 2013 "Obsidian" cultivar, the "Triple Crown" fruit from the 2013 early harvest showed significantly higher initial firmness than the late harvest fruit, again, likely due to the degree of berry ripeness. Firmness also decreased significantly during storage, with the firmness of the middle harvest fruit decreasing by $23.87 \%$ and that of the early harvest by $22.92 \%$ after $10-12 \mathrm{~d}$ of storage. These decreases in firmness generally agreed with the findings of PerkinsVeazie et al. [54] that commercially grown (CG) "Navaho" blackberries lost $36 \%$ firmness during refrigerated storage and Joo et al. [33] that CG "Chester" blackberries underwent a $35 \%$ decrease in firmness after $12 \mathrm{~d}$ of refrigerated storage.

3.4. Sugar Profiles. Figures 4 and 5 illustrate the sugar profiles of fruit from the 2012 harvest during refrigerated storage for "Obsidian" and "Triple Crown," respectively. The observed effects of fertilizer on total sugar content varied depending on cultivar, with "Obsidian," initial total sugar content ranged from 14.7 to $18.7 \mathrm{~g} / 100 \mathrm{~g} \mathrm{FW}$ and "Obsidian" fertilized with SM having the highest initial values in the early and middle harvests, and those fertilized with PPL having the highest in the late harvest, with SM fertilized berries having the highest values in the early and middle harvests, and PPL ones having the highest in the late harvest. Overall, the "Triple Crown" fruit had higher initial total sugar content than that of "Obsidian," ranging from 22.14 to $28.41 \mathrm{~g} / 100 \mathrm{~g} \mathrm{FW}$, with SM fertilized berries again having the highest values in the middle harvest, and PPL and FE fertilized fruits having the highest values in the early and late harvest, respectively. These fertilizer effects were hardly surprising, given that the three regimens likely have different rates of nitrogen release/absorption, and multiple studies have shown a relationship between available nitrogen and fruit sugars in diverse fruits such as strawberries, tomatoes, chokeberries, dates, and grapes, as well as potential influence of other trace minerals [57-61].

Examining individual sugars, overall, sucrose comprises a minor fraction $(2-3 \%$ for "Obsidian" and $0-7.4 \%$ for "Triple Crown") of the total sugars in all harvests, while fructose represented the major fraction in all harvests of the "Triple Crown" fruit, as well as the early harvest of the "Obsidian" fruit, but not the middle and late harvests, where glucose dominated. During storage, the ratio of sucrose to fructose remained fairly consistent throughout storage across all treatments and harvests in both cultivars, while the amount of sucrose showed a definite cultivar-specific response. The initial relative values agreed with previously 

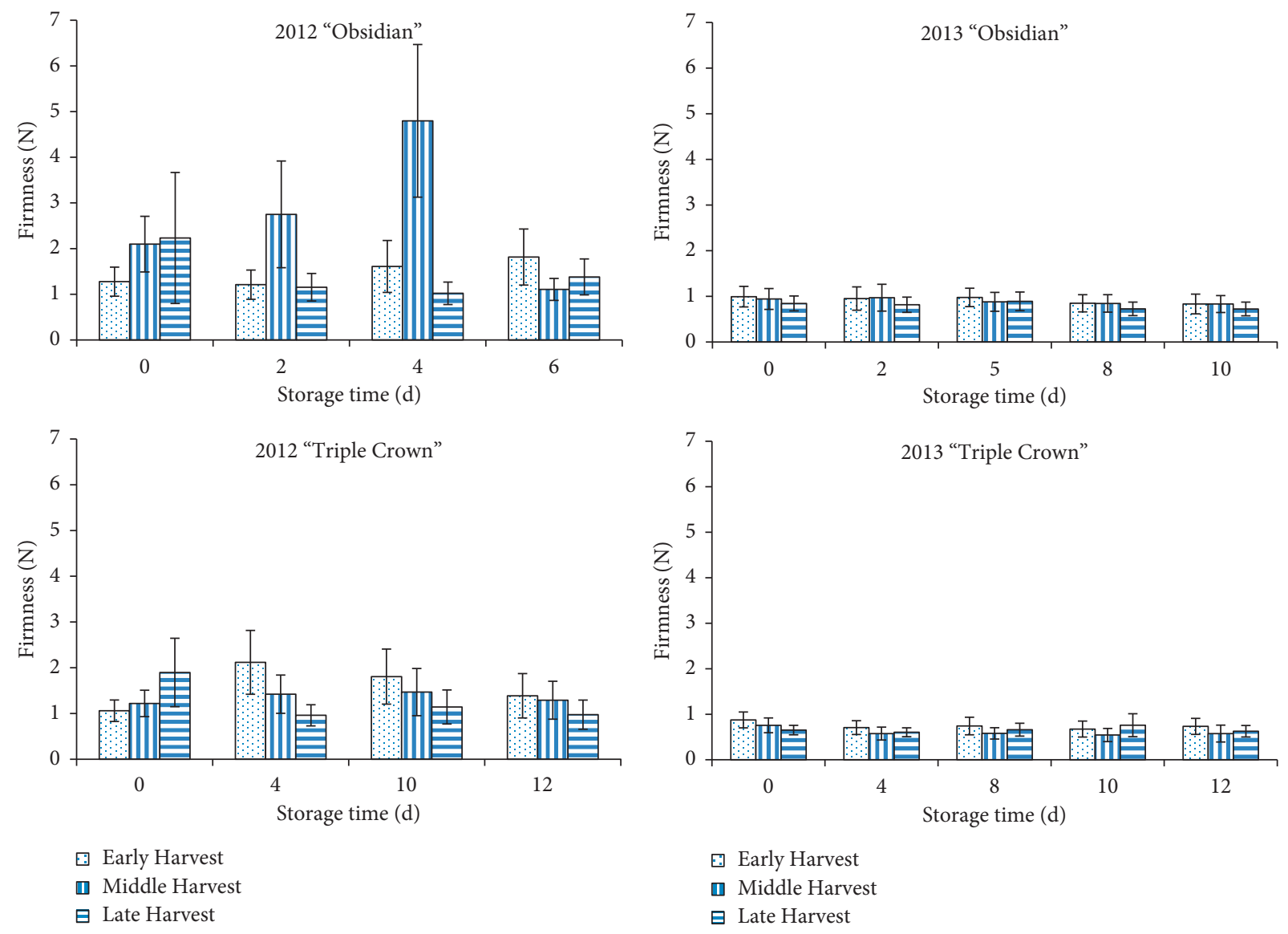

(a)

(b)

FiguRE 3: Effect of different harvest date and refrigerated storage on the firmness of two blackberry cultivars: "Obsidian" and "Triple Crown" at 2012 and 2013 harvest.

published data by Fan-Chiang [62] and Kafkas et al. [63] for other CG blackberry varieties, and the observed shift in predominant sugar during the "Obsidian" harvest might be explained as fruit harvested early in the season would be more likely to be underripe, thus less sweet. However, not only did the early harvest "Obsidian" fruit generally contained greater overall amount of sugar but also they showed higher proportions of fructose, which strongly implied that they would be perceived as sweeter, given that fructose is roughly twice as sweet as glucose and 1.7 times as sweet as sucrose $[64,65]$. By contrast, the "Triple Crown" fruit followed a more predictable pattern, with the middle and late harvests having higher initial values of both total sugars and fructose.

The effect of storage on the sugar profile tended to follow a trend of increasing slightly shortly after storage and then either leveling off, or declining slightly. Of the five harvest/ treatment combinations that did not follow this trend, four were fertilized with PPL (early and late harvest "Obsidian" and middle and late harvest "Triple Crown") and one was fertilized with FE (late harvest "Triple Crown"). These harvest/treatment combinations showed marked (as much as $30 \%$ ) increases in total sugars, which could be explained by a combination of postharvest ripening and the degradation of anthocyanins during storage, the latter of which released previously bound sugars [39], while the differences in fertilizer effect were likely related to the effects of different rates of nitrogen release on the average maturity of the harvested berries which would in turn show different trends in postharvest ripening.

Looking at individual sugars, the cultivar-specific response to storage is quite noticeable. Except in the early harvest, "Obsidian" berries had decreased sucrose levels as storage progressed, most likely due to sucrose hydrolysis due to metabolic processes in the fruit. "Triple Crown" berries, on the other hand, showed the opposite relationship, except for the SM-fertilized middle harvest berries, with the early harvest showing undetectable levels of sucrose across all storage periods, while the middle and late harvests actually showed significant increases in sucrose levels. While few studies have examined the effects of cold storage on the sugar profile of blackberries, other CG fruits were shown to undergo reductions in relative sucrose levels, including pears [66], strawberries [67], and peaches [68], and the downward trend observed in "Obsidian" was similar to the findings for raspberries and blackberries from Ali et al. [50]. Explaining the increases in sucrose seen in the early harvest "Obsidian" and middle/late harvest "Triple Crown" fruit was more 


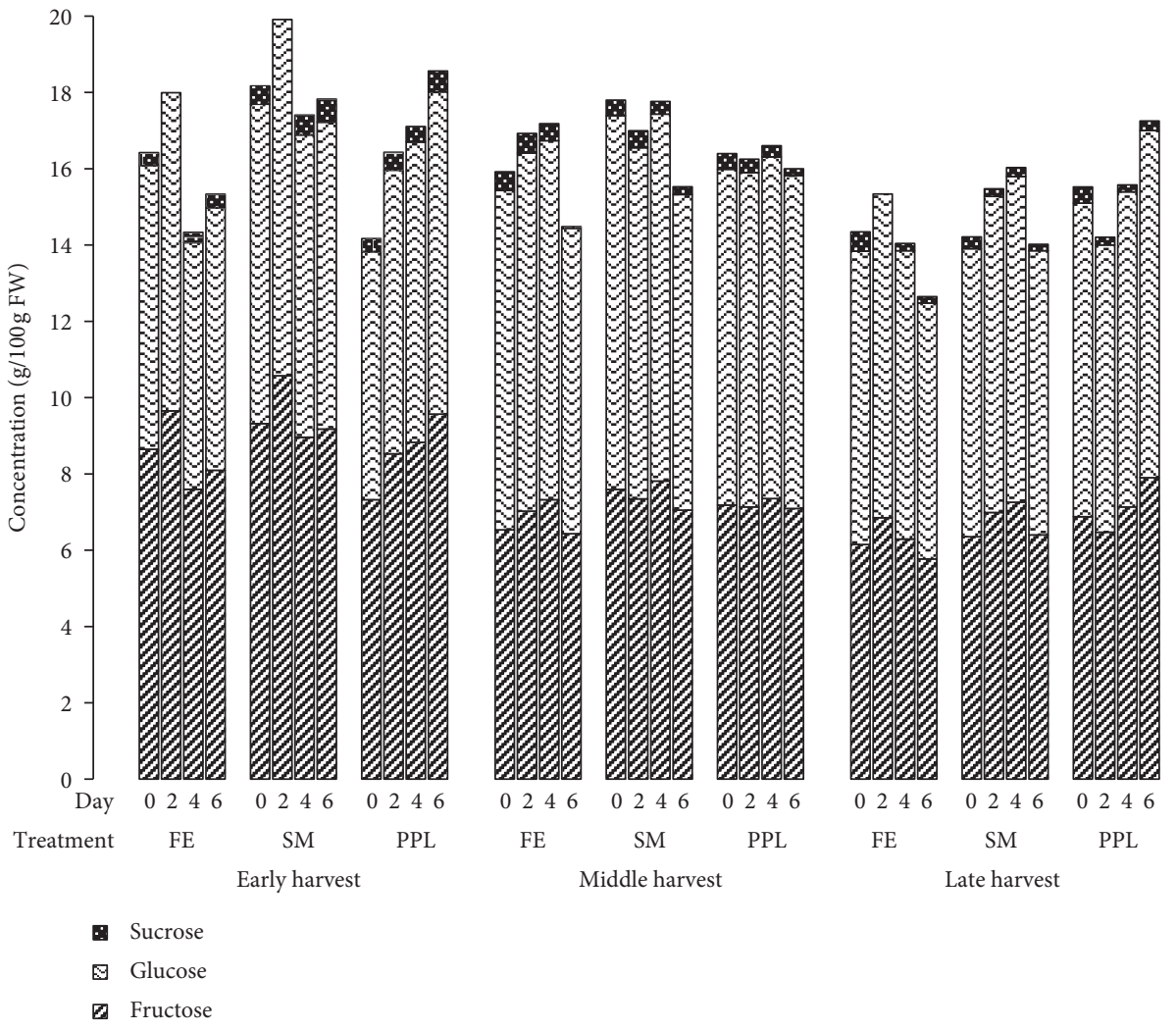

FIgURE 4: Sugar profile of "Obsidian," expressed in total concentration, 2012 harvest. FE: blend of fish emulsion and fish hydrolysate; SM: soy meal; PPL: processed poultry litter.
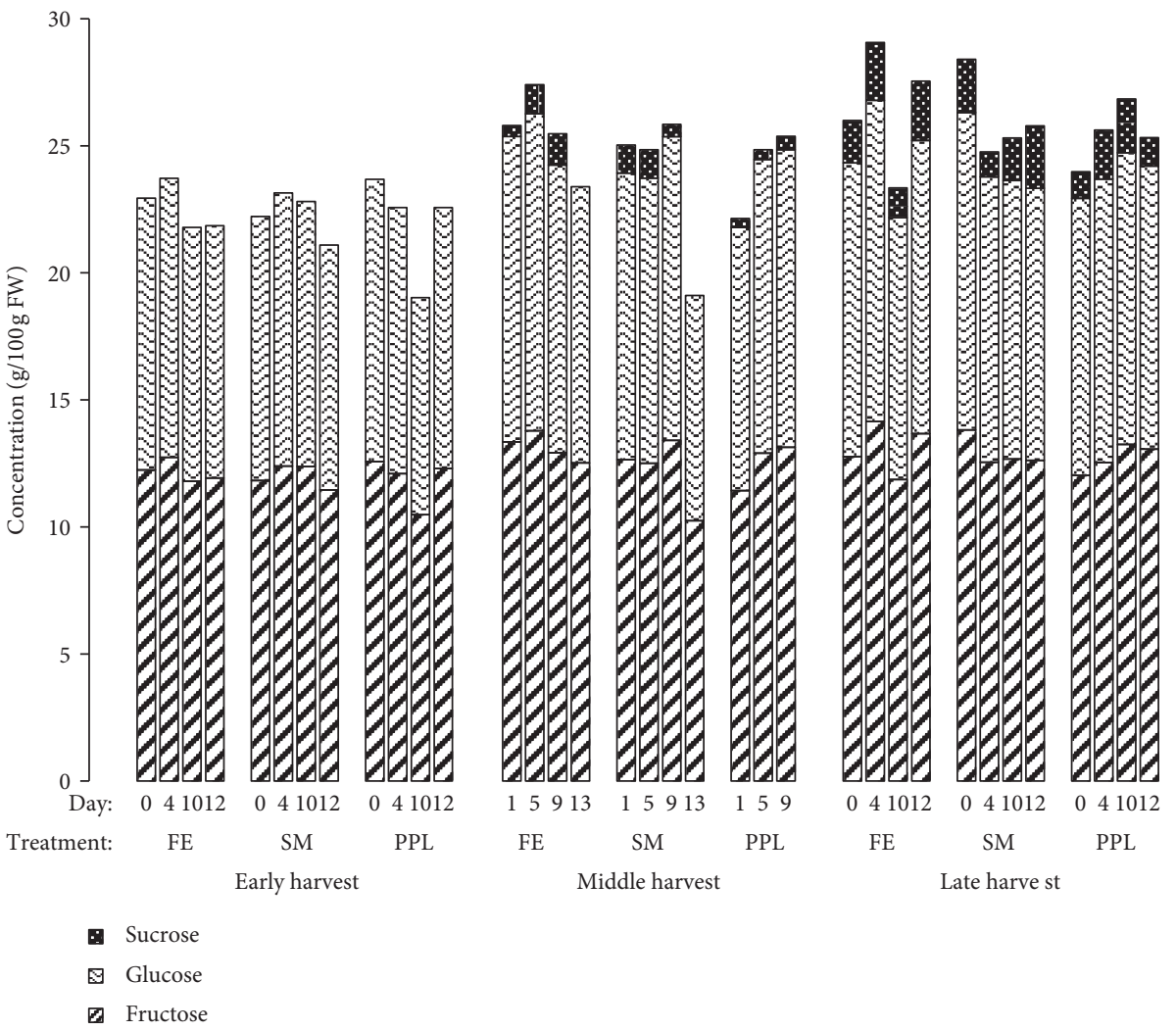

$$
\text { Glucose }
$$

FIgURE 5: Sugar profile of "Triple Crown," expressed in total concentration, 2012 harvest. FE: blend of fish emulsion and fish hydrolysate; SM: soy meal; PPL: processed poultry litter. 
difficult, particularly in the latter as it was so pronounced. One possibility was that these fruits were slightly undermature when picked, and underwent ripening during storage, as was explained for the changes in antioxidant measures. This could have resulted in an increase in sucrose metabolism, as was observed in strawberries [65] and peaches [66], with the latter showing differences in behavior based upon degree of fruit ripeness.

3.5. Phenolic Content and Antioxidant Capacity. As previous studies have indicated significant year-to-year variability in antioxidant content and capacity [29, 69], antioxidant analysis was only performed on fruits from the 2012 harvest. Table 1 presents the initial (day of harvest) TPC and TMA values for both cultivars, while the three measures of antioxidant capacity (DPPH, ORAC, and FRAP) are presented in Table 2. In general, "Obsidian" fruits had higher antioxidant content, with values ranging 3.31-4.85 mg GAE/g for TPC and 2.28-3.51 mg/g for TMA, than "Triple Crown" fruits, which ranged $2.71-4.39 \mathrm{mg} \mathrm{GAE} / \mathrm{g}$ and $1.89-2.65 \mathrm{mg} / \mathrm{g}$, and a similar trend was seen in the measures of antioxidant capacity, with "Obsidian" having higher values than "Triple Crown" in DPPH (8.44-10.84 mg AAE/g vs. 6.61-7.89 mg AAE/g), ORAC (289.52-763.73 $\mu \mathrm{Mol} \mathrm{TE} / \mathrm{g}$ vs. $253.09-467.42 \mu \mathrm{Mol} \mathrm{TE} / \mathrm{g})$, and FRAP $\quad\left(596.05-791.71 \mu \mathrm{Mol} \mathrm{Fe}^{2+} / \mathrm{g}\right.$ vs. $489.67-646.68 \mu \mathrm{Mol}$ $\left.\mathrm{Fe}^{2+} / \mathrm{g}\right)$ ).

Examining the measures of a given harvest date and fertilizer combination found that the "Triple Crown" fruit had lower measures of both content and capacity than the corresponding combination for "Obsidian," with the sole exception being the ORAC values for the early harvest which were 4.4-61.4\% higher in "Triple Crown," depending on the fertilizer source.

The effect of refrigerated storage was quite erratic, with some samples showing increases in both amount of antioxidant contents (TPC and TMA) as well as antioxidant capacity (DPPH, ORAC, and FRAP), while others showed marked decreases in the same measurements. Figure 6 presents the relative changes in TPC and TMA, and Figure 7 reports the relative change in DPPH, ORAC, and FRAP. In all cases, the relative change was calculated using

$$
\text { relative } \text { value }_{\text {day } X}(\%)=\frac{\text { mean measurement at day } X}{\text { initial mean measurement }} \text {. }
$$

3.6. Initial Measures of Antioxidants. The values generally fall within the ranges reported for CG berries from the same two cultivars by Siriwoharn et al. [29] and Moyer et al. [69]. While the purpose of the current work was not to compare the two cultivars directly, it is important to note that, for all TPC, TMA, and DPPH measurements, the "Triple Crown" fruit showed lower values overall compared with "Obsidian" berries. Further, with the exception of the early harvest ORAC values (Table 2), the measures of a given harvest date and fertilizer combination for "Triple Crown" berries were also lower than the corresponding combination for
"Obsidian" except the ORAC value in the early harvest "Triple Crown." The overall trend agreed with the previous findings from Moyer et al. [69], which showed similar results for CG berries of the two cultivars. Regarding the different behaviors seen in the early harvest ORAC, the explanation could be the differences in berry maturity between the samples taken during the two early harvests, as previous studies on CG berries have shown that ORAC values increase over $40 \%$ during the transition of fruits from underripe to overripe [29].

The data also revealed a complex interplay between fertilizer type and harvest date. As it was expected, the harvest date had a significant effect on the antioxidant properties of the fruit, and the effect varied depending on the fertilizer applied. In general, the middle harvest fruit showed the highest TPC, TMA, and DPPH values in both cultivars, excepting the FE samples and the TMA of "Triple Crown" which both showed increased values during the late harvest date. These results were hardly a surprising, as harvests from later in the season were more likely to include ripe or overripe fruit than earlier harvest, and an increase in anthocyanins, the primary red/blue/purple pigments in fruits [70], have been observed in a variety of CG berry and nonberry fruits as they become more mature [29, 71, 72]. Furthermore, the observed differences in FE fertilized samples were likely due to the differences in application regimen mentioned above. By contrast, the effect of harvest date on FRAP and ORAC values varied depending on the cultivar (Table 2), with the late harvest fruit showing lower values compared to the early harvest among the "Triple Crown" berries (except for the FRAP of SM samples which showed the highest value in the late harvest), while the "Obsidian" berries showed the lowest ORAC values, but the highest FRAP values in the early harvest. This could be caused by a variety of factors, including the aforementioned nutrient stress, as well as climate/weather conditions, as the middle/late harvest of "Obsidian" and the early/middle harvest of "Triple Crown" both experienced higher temperatures and greater sunlight. This increase in sunlight exposure was important, as one of the principle reasons hypothesized for the existence of plant phenolics is protection from photooxidation; i.e., the plant produces antioxidant phenolic compounds in order to quench radicals generated by exposure to UV [73]. Hence, fruits exposed to higher levels of UV would register lower overall values in assays that rely upon the quenching of radicals, as the activity of the compounds would already have been depleted quenching the ROS from UV exposure.

The trends observed among the fertilizer treatments were likely best explained by two factors: differences in application methods and differences in soil/plant responses to the fertilizers. Regarding application method, while all fertilizers were applied at the same rate, there were two different application schedules-SM and PPL, being pelletized products, were applied a single time, while FE was applied in four intervals, the final of which occurred shortly prior to the beginning of the harvest season, after the plants had bloomed [27]. This application schedule likely provided the plants receiving $\mathrm{FE}$ 
TABle 1: Total phenolic content and monomeric anthocyanins at harvest for cultivars "Obsidian" and "Triple Crown," 2012 harvest ${ }^{\dagger}$.

\begin{tabular}{|c|c|c|c|}
\hline & Fish emulsion/hydrolysate blend & Soy meal & Processed poultry litter \\
\hline \multicolumn{4}{|l|}{ TPC (mg GAE/g) } \\
\hline \multicolumn{4}{|l|}{ Obsidian } \\
\hline Early harvest & $\mathrm{A} 3.31 \pm 0.08^{\mathrm{a}}$ & $\mathrm{B} 3.86 \pm 0.10^{\mathrm{a}}$ & $\mathrm{B} 4.05 \pm 0.21^{\mathrm{a}}$ \\
\hline Middle harvest & $\mathrm{A} 4.21 \pm 0.02^{\mathrm{a}}$ & $\mathrm{B} 5.55 \pm 0.15^{\mathrm{b}}$ & $\mathrm{A} 4.30 \pm 0.15^{\mathrm{b}}$ \\
\hline Late harvest & $\mathrm{A} 4.85 \pm 0.23^{\mathrm{c}}$ & $\mathrm{B} 4.59 \pm 0.06^{\mathrm{c}}$ & $\mathrm{C} 3.54 \pm 0.11^{\mathrm{c}}$ \\
\hline \multicolumn{4}{|l|}{ Triple crown } \\
\hline Early harvest & $\mathrm{A} 3.030 \pm 0.07^{\mathrm{a}}$ & $\mathrm{B} 3.76 \pm 0.14^{\mathrm{a}}$ & $\mathrm{C} 3.42 \pm 0.06^{\mathrm{a}}$ \\
\hline Middle harvest & $\mathrm{A} 2.96 \pm 0.07^{\mathrm{a}}$ & $\mathrm{B} 3.81 \pm 0.09^{\mathrm{a}}$ & $\mathrm{C} 4.39 \pm 0.12^{\mathrm{b}}$ \\
\hline Late harvest & $\mathrm{A} 3.55 \pm 0.18^{\mathrm{b}}$ & $\mathrm{B} 2.89 \pm 0.05^{\mathrm{b}}$ & $\mathrm{C} 2.71 \pm 0.05^{\mathrm{c}}$ \\
\hline \multicolumn{4}{|l|}{$\mathrm{TMA}(\mathrm{mg} / \mathrm{g})^{\ddagger}$} \\
\hline \multicolumn{4}{|l|}{ Obsidian } \\
\hline Early harvest & $\mathrm{A} 2.28 \pm 0.11^{\mathrm{a}}$ & $\mathrm{A} 2.51 \pm 0.14^{\mathrm{a}}$ & $\mathrm{A} 2.45 \pm 0.11^{\mathrm{a}}$ \\
\hline Middle harvest & $\mathrm{A} 3.16 \pm 0.20^{\mathrm{b}}$ & $\mathrm{B} 3.51 \pm 0.24^{\mathrm{b}}$ & $\mathrm{C} 3.10 \pm 0.19^{\mathrm{b}}$ \\
\hline Late harvest & $\mathrm{A} 3.17 \pm 0.22^{\mathrm{b}}$ & $\mathrm{B} 3.11 \pm 0.21^{\mathrm{c}}$ & $\mathrm{B} 2.56 \pm 0.16^{\mathrm{a}}$ \\
\hline \multicolumn{4}{|l|}{ Triple crown } \\
\hline Early harvest & $\mathrm{A} 1.89 \pm 0.00^{\mathrm{a}}$ & $\mathrm{A} 1.93 \pm 0.08^{\mathrm{a}}$ & $\mathrm{A} 2.08 \pm 0.08^{\mathrm{a}}$ \\
\hline Middle harvest & $\mathrm{A} 2.39 \pm 0.08^{\mathrm{b}}$ & $\mathrm{B} 2.10 \pm 0.03^{\mathrm{b}}$ & $\mathrm{B} 2.14 \pm 0.04^{\mathrm{a}}$ \\
\hline Late harvest & $\mathrm{A} 2.65 \pm 0.02^{\mathrm{b}}$ & $\mathrm{A} 2.57 \pm 0.03^{\mathrm{c}}$ & $\mathrm{B} 2.57 \pm 0.05^{\mathrm{b}}$ \\
\hline
\end{tabular}

TPC: total phenolic content; TMA: total monomeric anthocyanins. ${ }^{\dagger}$ Mean values \pm SD, $n=3$. Values preceded with the same capital letters (A-C) within the same row of a given table are not statistically different $(\alpha \leq 0.05) .{ }^{\ddagger}$ Within a given cultivar and phenolic determination method, values followed with the same lowercase letters $(\mathrm{a}-\mathrm{c})$ within the same column of a given table are not statistically different $(\alpha \leq 0.05)$.

Table 2: Antioxidant capacity of "Obsidian" and "Triple Crown" blackberry cultivars at harvest (2012 harvest).

\begin{tabular}{|c|c|c|c|}
\hline & Fish emulsion/hydrolysate blend & Soy meal & Processed poultry litter \\
\hline \multicolumn{4}{|l|}{$\mathrm{DPPH}(\mathrm{mg} \mathrm{AAE} / \mathrm{g})^{\dagger \neq}$} \\
\hline \multicolumn{4}{|l|}{ Obsidian } \\
\hline Early harvest & $\mathrm{A} 8.44 \pm 0.75^{\mathrm{a}}$ & $\mathrm{A} 8.77 \pm 0.52^{\mathrm{a}}$ & $\mathrm{A} 7.78 \pm 0.21^{\mathrm{a}}$ \\
\hline Middle harvest & $\mathrm{A} 9.94 \pm 1.04^{\mathrm{a}}$ & $\mathrm{A} 10.84 \pm 0.13^{\mathrm{b}}$ & $\mathrm{A} 9.26 \pm 0.15^{\mathrm{b}}$ \\
\hline Late harvest & $\mathrm{A} 10.01 \pm 0.31^{\mathrm{a}}$ & A $9.20 \pm 0.90^{\mathrm{a}}$ & A $8.98 \pm 0.11^{c}$ \\
\hline \multicolumn{4}{|l|}{ Triple crown } \\
\hline Early harvest & $\mathrm{A} 6.96 \pm 0.29^{\mathrm{a}}$ & $\mathrm{A} 6.63 \pm 1.18^{\mathrm{a}}$ & $\mathrm{A} 6.68 \pm 0.06^{\mathrm{a}}$ \\
\hline Middle harvest & $\mathrm{A} 6.61 \pm 0.28^{\mathrm{a}}$ & $\mathrm{A} 7.61 \pm 0.58^{\mathrm{a}}$ & $\mathrm{A} 7.98 \pm 0.12^{\mathrm{b}}$ \\
\hline Late harvest & $\mathrm{A} 7.70 \pm 0.68^{\mathrm{a}}$ & $\mathrm{A} 6.80 \pm 0.47^{\mathrm{a}}$ & $\mathrm{A} 6.63 \pm 0.05^{\mathrm{c}}$ \\
\hline \multicolumn{4}{|c|}{ ORAC $(\mu \mathrm{mol} \mathrm{TE} / \mathrm{g})^{\dagger * \#}$} \\
\hline \multicolumn{4}{|l|}{ Obsidian } \\
\hline Early harvest & $\mathrm{A} 289.52 \pm 22.57^{\mathrm{a}}$ & $\mathrm{B} 427.86 \pm 27.86^{\mathrm{a}}$ & $\mathrm{B} 392.54 \pm 0.11^{\mathrm{a}}$ \\
\hline Middle harvest & $\mathrm{A} 380.48 \pm 9.79^{\mathrm{b}}$ & $\mathrm{B} 501.69 \pm 0.51^{\mathrm{b}}$ & $\mathrm{A} 416.80 \pm 0.19^{\mathrm{b}}$ \\
\hline Late harvest & $\mathrm{A} 763.73 \pm 18.39^{\mathrm{c}}$ & $\mathrm{B} 717.15 \pm 55.05^{\mathrm{c}}$ & $\mathrm{C} 591.50 \pm 0.16^{\mathrm{a}}$ \\
\hline \multicolumn{4}{|l|}{ Triple crown } \\
\hline Early harvest & $\mathrm{A} 467.42 \pm 36.00^{\mathrm{a}}$ & $\mathrm{A} 446.88 \pm 5.89^{\mathrm{a}}$ & $\mathrm{A} 427.55 \pm 0.08^{\mathrm{a}}$ \\
\hline Middle harvest & $\mathrm{A} 362.66 \pm 12.78^{\mathrm{b}}$ & $\mathrm{B} 403.50 \pm 12.65^{\mathrm{b}}$ & $\mathrm{A} 387.89 \pm 0.04^{\mathrm{a}}$ \\
\hline Late harvest & $\mathrm{A} 253.09 \pm 5.69^{\mathrm{c}}$ & $\mathrm{A} 268.04 \pm 24.43^{\mathrm{C}}$ & $\mathrm{A} 253.71 \pm 0.05^{\mathrm{b}}$ \\
\hline \multicolumn{4}{|c|}{ FRAP $\left(\mu \mathrm{mol} \mathrm{Fe} e^{2+} / \mathrm{g}\right)^{\dagger * \#}$} \\
\hline \multicolumn{4}{|l|}{ Obsidian } \\
\hline Early harvest & $\mathrm{A} 753.51 \pm 0.06^{\mathrm{a}}$ & $\mathrm{A} 791.71 \pm 0.00^{\mathrm{a}}$ & $A 767.75 \pm 6.60^{\mathrm{a}}$ \\
\hline Middle harvest & $\mathrm{A} 596.05 \pm 60.21^{\mathrm{b}}$ & $\mathrm{B} 727.32 \pm 11.85^{\mathrm{b}}$ & $\mathrm{A} 649.29 \pm 2.05^{\mathrm{b}}$ \\
\hline Late harvest & $\mathrm{A} 709.10 \pm 6.39^{\mathrm{a}}$ & $\mathrm{A} 680.87 \pm 34.27^{\mathrm{b}}$ & $\mathrm{B} 622.75 \pm 5.66^{\mathrm{b}}$ \\
\hline \multicolumn{4}{|l|}{ Triple crown } \\
\hline Early harvest & $\mathrm{A} 521.53 \pm 4.35^{\mathrm{a}}$ & $\mathrm{B} 588.15 \pm 3.04^{\mathrm{a}}$ & $\mathrm{A} 534.38 \pm 1.06^{\mathrm{a}}$ \\
\hline Middle harvest & $\mathrm{A} 489.67 \pm 3.06^{\mathrm{b}}$ & $\mathrm{B} 548.21 \pm 13.17^{\mathrm{b}}$ & $\mathrm{C} 600.98 \pm 9.18^{\mathrm{b}}$ \\
\hline Late harvest & $\mathrm{A} 646.48 \pm 13.73^{\mathrm{C}}$ & B574.66 $\pm 10.10^{\mathrm{a}}$ & $\mathrm{B} 559.62 \pm 5.37^{\mathrm{c}}$ \\
\hline
\end{tabular}

DPPH: radical scavenging activity by the 2,2-diphenyl-1-picrylhydrazyl colorimetric method; ORAC: oxygen radical absorbance capacity; FRAP: ferricreducing antioxidant power. ${ }^{\dagger}$ Mean values $\pm S D, n=3 .{ }^{\ddagger}$ Mean values $\pm S D, n=2 .{ }^{*}$ Values preceded with the same capital letters (A-C) within the same row of a given table are not statistically different $(\alpha \leq 0.05) .{ }^{\#}$ Within a given cultivar and antioxidant method, values followed with the same lowercase letters $(\mathrm{a}-\mathrm{c})$ within the same column of a given table are not statistically different $(\alpha \leq 0.05)$.

fertilizer a more uniform amount of nutrients, allowing for greater reserves during fruit development and maturation. In addition to the application schedules, the properties of the individual fertilizer types might also play a role, as it has been shown that fertilizer source and form can have a profound effect on short-term availability of 


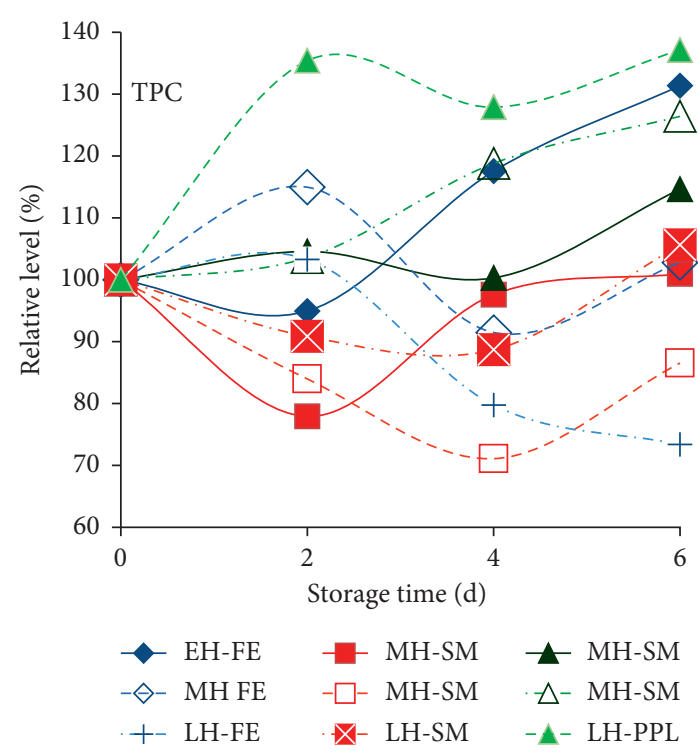

(a)

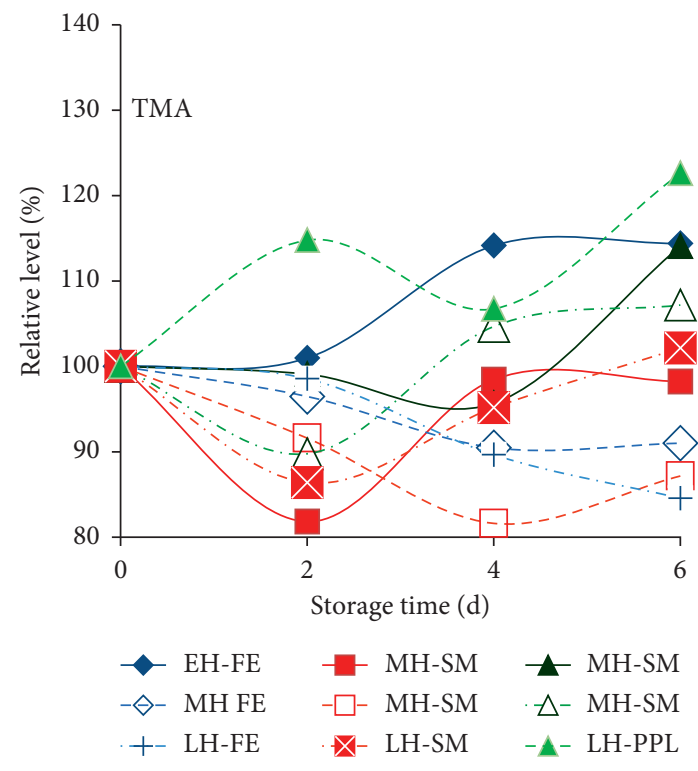

(c)

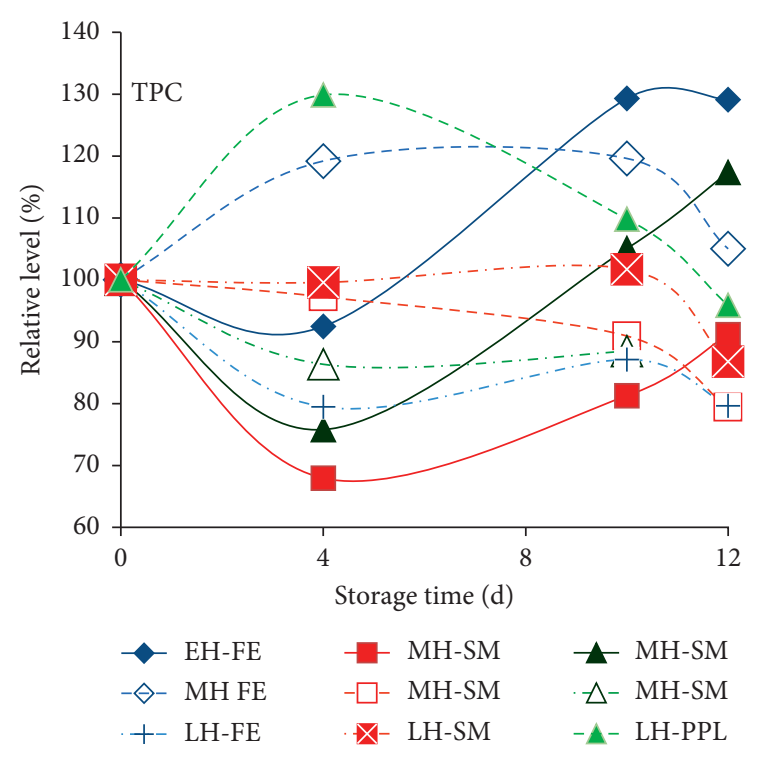

(b)

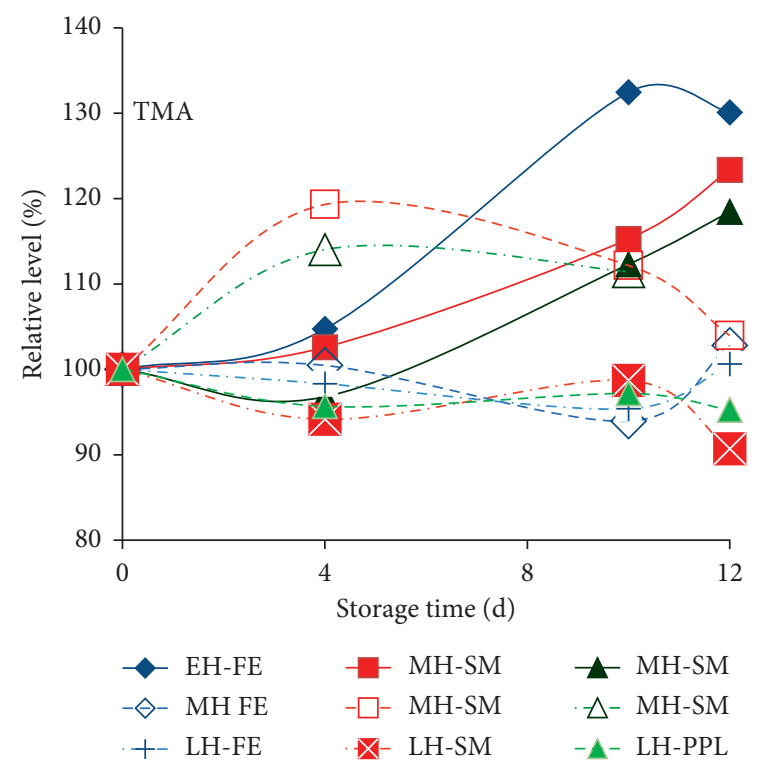

(d)

Figure 6: Relative phenolic content and monomeric anthocyanins during storage of two blackberry cultivars: "Obsidian" (a) and "Triple Crown” (b), 2012 harvest. FE: blend of fish emulsion and fish hydrolysate; SM: soy meal; PPL: processed poultry litter.

nutrients in the soil, with composted fertilizers having the smallest immediate effect, animal slurries having some of the highest, and legume meals falling somewhere in between [74]. Since it is well known that plants respond to various stresses in complex ways, typically involving the use of reactive oxygen species (ROS) as mechanisms for signaling various types of stress, from drought to pollutants to excess UV to diseases [75, 76], it is possible that if the nitrogen release rates of the various fertilizer types result in a dearth of available nutrients, this stress would be similarly signaled, affecting the antioxidant content of the resulting fruit. Such behavior has been seen in multiple plant species, with increased fertilization, particularly prior to flowering, reducing the levels of various antioxidants in fruits $[73,77,78]$.

3.7. Effect of Storage on Antioxidants. Storage had a very erratic effect on both the antioxidant content and capacity, with many harvest/fertilizer treatments showing increases in either or both during storage. While these increases might be counterintuitive, this was not the first time such trends have been noticed. Wu et al. [35] found similar trends in the CG blackberry cultivars they examined, Kalt et al. [79] also observed increases in various CG small fruits, including raspberries, and Ali et al. [50] reported increases in ellagic acid in 


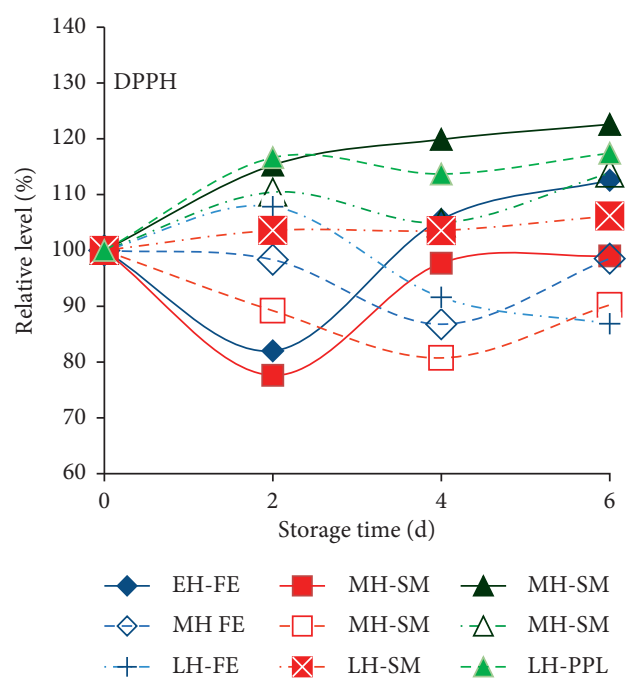

(a)

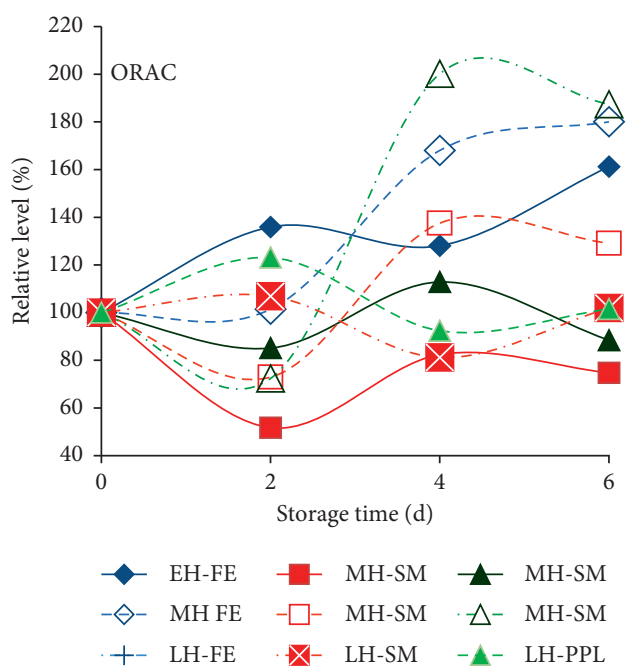

(c)

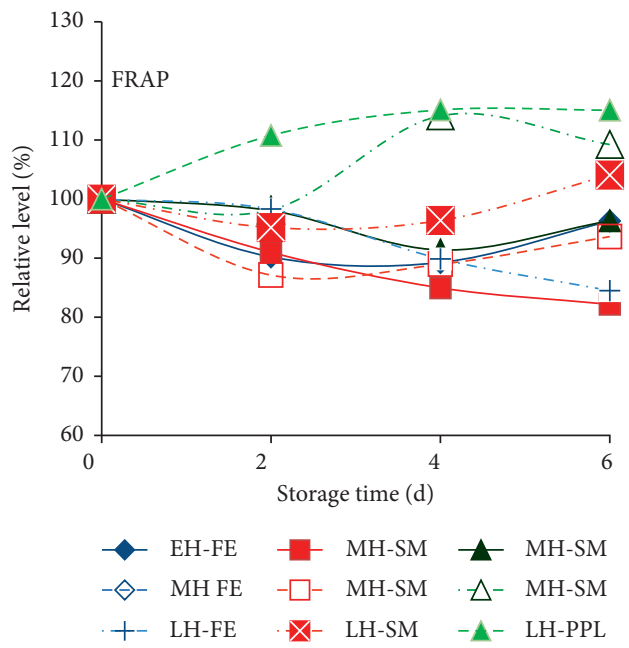

(e)

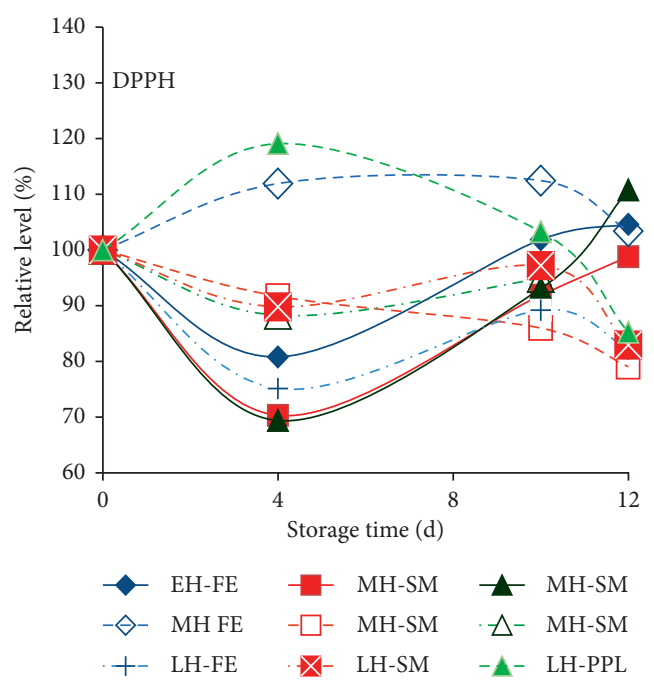

(b)

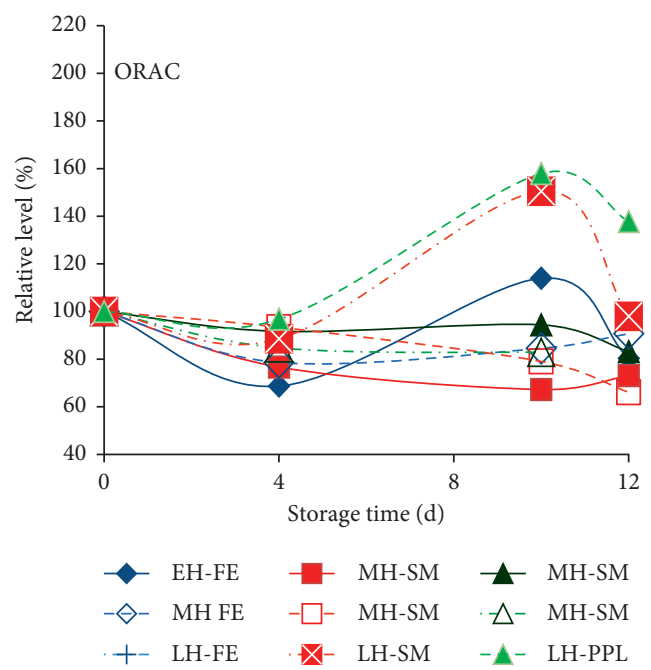

(d)

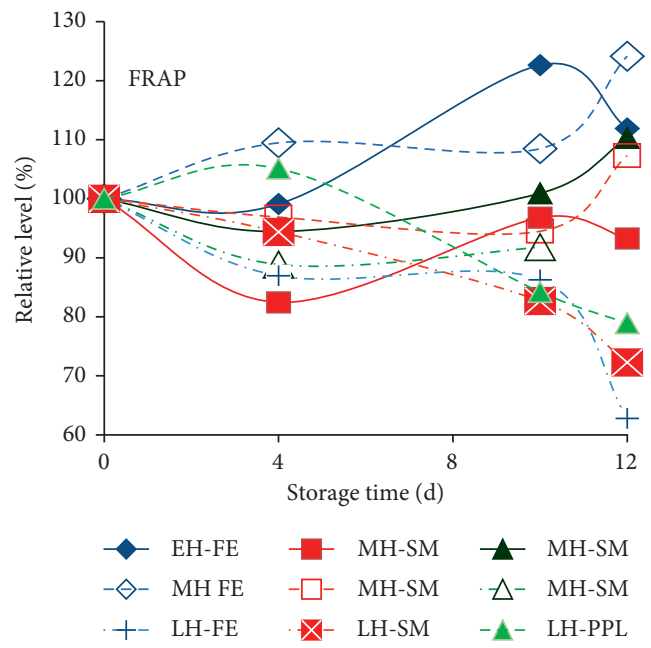

(f)

FIgURE 7: Relative antioxidant potential by three methods (DPPH, ORAC, and FRAP) during storage of two blackberry cultivars: "Obsidian" (a) and "Triple Crown" (b), 2012 harvest. FE: blend of fish emulsion and fish hydrolysate; SM: soy meal; PPL: processed poultry litter. 
late-harvest CG blackberries and raspberries, as well as increases in anthocyanins and total phenolics in raspberries. While metabolic mechanisms were indicated in these rises, there were some debates over what initiated the process, with possibilities ranging from normal ripening of the potentially undermature fruit to the breakdown of other fruit components (notably organic acids), creating additional carbon skeletons to feed the pathways that synthesized phenolic compounds $[35,79]$. In addition, it was also possible that the stimulus for the production is related to the aforementioned plant responses to stress [76], as it could be expected that refrigeration at $4^{\circ} \mathrm{C}$ would create temperature stresses in the summer fruit, and such behavior was noted in CG tomatoes, watermelons, apples, strawberries, and mangoes [66, 80-82].

\section{Conclusion}

In organically grown blackberries, the use of different fertilizers had virtually no significant effect on the physicochemical properties of "Obsidian" and "Triple Crown" blackberry fruit at the time of harvest and during the refrigerated storage, but did have a profound effect on the measures of antioxidant content, antioxidant capacity, and the composition of sugars. Furthermore, these measures were also affected by differences in blackberry cultivar, harvest date, and storage time, with the interaction between the factors showing great complexity. Despite this, several general observations could be made, namely, that with respect to both antioxidant measures and sugar profiles, fertilization with either a fish emulsion/fish hydrolyate or soy meal-based fertilizers were preferable to the use of processed poultry litter, that during storage ripening tended to increase the relative levels of fructose at the expense of decreasing sucrose content and that while the middle harvest had higher initial levels of phenolic compounds, including anthocyanins, and their antioxidant capacity followed less predictable trends, particularly in the "Triple Crown" cultivar. Further, the organically grown "Obsidian" fruit may be marketed for fresh consumption within $4 \mathrm{~d}$ after harvest while the "Triple Crown" fruit can be extended for $8 \mathrm{~d}$ due to its lower rates of decay and leakage. While further study is needed to elaborate the mechanisms involved and how well these findings can be applied over other cultivars, it is entirely likely that the fertilizer regimen might be able to be used to maximize the healthful properties of blackberries, and potentially in other fruits, while having a negligible effect on traditional physicochemical measures of quality.

\section{Data Availability}

All the data related to this article are described in Tables 1 and 2 and/or depicted in Figures 1-7. Persons interested in the raw data may contact the corresponding author to receive a copy.

\section{Conflicts of Interest}

The authors declare that there are no conflicts of interest regarding the publication of this paper.

\section{Acknowledgments}

The authors would like to thank the USDA AFRI Organic Research Initiative for funding this project (Project no. 2008-01237), Mr. Eric Pond of Riverbend Organic Farms for his assistance in growing and providing berry samples, and Dr. Xiaoyuan Feng, Dr. Jooyeoun Jung, and Ms. Angela Tseng for their assistance with sample collection/preparation during the harvest. Harvest was carried out onsite at Riverbend Organic Farms, and all the analytical works were performed at the Oregon State University, either in the Department of Food Science or at the Linus Pauling Institute.

\section{References}

[1] USDA, Data Products: Organic Production, E. R. Service, Lanham, MD, USA, 2010, https://www.ers.usda.gov/dataproducts/organic-production.aspx\#.UdSsHG0kxc4.

[2] OTA, Seventy-Eight Percent of U.S. Families Say they Purchase Organic Foods, Organic Trade Association, Ottawa, ON, Canada, 2011, http://www.organicnewsroom.com/2011/11/ seventyeight_percent_of_us_fam.html.

[3] A. Srivastava, "Phenolic constituents of georgia-grown blackberry cultivars: fractionation and characterization of their antioxidant, radicalscavenging,and anti-inflammatory capacities," in Food Science and Technology, p. 330, University of Georgia, Athens, Georgia, 2009.

[4] B. L. Halvorsen, K. Holte, M. C. W. Myhrstad et al., "A systematic screening of total antioxidants in dietary plants," The Journal of Nutrition, vol. 132, no. 3, pp. 461-471, 2002.

[5] L.-S. Wang, S. S. Hecht, S. G. Carmella et al., "Anthocyanins in black raspberries prevent esophageal tumors in rats," Cancer Prevention Research, vol. 2, no. 1, pp. 84-93, 2009.

[6] M. Obrenovich, Y. Li, K. Parvathaneni et al., "Antioxidants in health, disease and aging," CNS \& Neurological Disorders Drug Targets, vol. 10, no. 2, pp. 192-207, 2011.

[7] S.-Y. Kang, N. P. Seeram, M. G. Nair, and L. D. Bourquin, "Tart cherry anthocyanins inhibit tumor development in ApcMin mice and reduce proliferation of human colon cancer cells," Cancer Letters, vol. 194, no. 1, pp. 13-19, 2003.

[8] A. Hagiwara, K. Miyashita, T. Nakanishi et al., "Pronounced inhibition by a natural anthocyanin, purple corn color, of 2-amino-1-methyl-6-phenylimidazo[4,5-b]pyridine (PhIP)-associated colorectal carcinogenesis in male F344 rats pretreated with 1,2-dimethylhydrazine," Cancer Letters, vol. 171, no. 1, pp. 17-25, 2001.

[9] B. C. Strik, J. R. Clark, C. E. Finn, and M. P. Bañados, "Worldwide blackberry production," HortTechnology, vol. 17, pp. 205-213, 2007.

[10] B. C. Strik, "A review of nitrogen nutrition of Rubus," in Proceedings of the IX International Rubus and Ribes Symposium, vol. 777, Pucón, Chile, December 2005.

[11] J. Naraguma and J. R. Clark, "Effect of nitrogen fertilization on "arapaho" thornless blackberry," Communications in Soil Science and Plant Analysis, vol. 29, no. 17-18, pp. 2775-2783, 1998.

[12] G. L. Kuepper, H. Born, and J. Bachmann, "Organic culture of bramble fruits," in National Sustainable Agricultural Information Service, ATTRA, Publication\# IP022, Fayetteville, AR, USA, 2003. 
[13] J. P. Reganold, P. K. Andrews, J. R. Reeve et al., "Fruit and soil quality of organic and conventional strawberry agroecosystems," PLoS ONE, vol. 5, no. 9, Article ID e12346, 2010.

[14] G. Györe-Kis, K. Deák, A. Lugasi, A. Csúr-Vargaa, and L. Helyes, "Comparison of conventional and organic tomato yield from a three-year-term experiment," Acta Alimentaria, vol. 41, no. 4, pp. 486-493, 2012.

[15] E. Hallmann, "The influence of organic and conventional cultivation systems on the nutritional value and content of bioactive compounds in selected tomato types," Journal of the Science of Food and Agriculture, vol. 92, no. 14, pp. 2840-2848, 2012.

[16] M. S. Macoris, R. De Marchi, N. S. Janzantti, and M. Monteiro, "The influence of ripening stage and cultivation system on the total antioxidant activity and total phenolic compounds of yellow passion fruit pulp," Journal of the Science of Food and Agriculture, vol. 92, no. 9, pp. 1886-1891, 2012.

[17] A. M. Griffiths, D. M. Cook, D. L. Eggett, and M. J. Christensen, "A retail market study of organic and conventional potatoes (Solanum tuberosum): mineral content and nutritional implications," International Journal of Food Sciences and Nutrition, vol. 63, no. 4, pp. 393-401, 2012.

[18] M. Gaskell and R. Smith, "Nitrogen sources for organic vegetable crops," HortTechnology, vol. 17, no. 4, pp. 431-441, 2007.

[19] P. M. Berry, R. Sylvester-Bradley, L. Philipps et al., "Is the productivity of organic farms restricted by the supply of available nitrogen?," Soil Use and Management, vol. 18, no. 3, pp. 248-255, 2002.

[20] L. R. Bulluck, M. Brosius, G. K. Evanylo, and J. B. Ristaino, "Organic and synthetic fertility amendments influence soil microbial, physical and chemical properties on organic and conventional farms," Applied Soil Ecology, vol. 19, no. 2, pp. 147-160, 2002.

[21] C. H. Crisosto, F. G. Mitchell, and S. Johnson, "Factors in fresh market stone fruit quality," Postharvest News and Information, vol. 6, no. 2, pp. 17-21, 1995.

[22] R. Dris, R. Niskanen, and E. Fallahi, "Nitrogen and calcium nutrition and fruit quality of commercial apple cultivars grown in Finland," Journal of Plant Nutrition, vol. 21, no. 11, pp. 2389-2402, 1998.

[23] T. P. D. Santos, C. M. Lopes, M. L. Rodrigues et al., "Partial rootzone drying: effects on growth and fruit quality of fieldgrown grapevines (Vitis vinifera)," Functional Plant Biology, vol. 30, no. 6, pp. 663-671, 2003.

[24] R. H. Harkins, B. C. Strik, and D. R. Bryla, "Weed management practices for organic production of trailing blackberry: I. Plant growth and early fruit production," HortScience, vol. 48, no. 9, pp. 1139-1144, 2013.

[25] F. M. Basiouny, "Ethylene evolution and quality of blackberry fruit as influenced by harvest time and storage intervals," Acta Horticulturae, vol. 398, pp. 195-204, 1995.

[26] E. Thompson, B. C. Strik, E. Finn, Y. Zhao, and J. R. Clark, "High tunnel versus open field: management of primocanefruiting blackberry using pruning and tipping to increase yield and extend the fruiting season," HortScience, vol. 44, no. 6, pp. 1581-1587, 2009.

[27] J. Fernandez-Salvador, B. Strik, and D. Bryla, "Impact of organic fertilizer source on the yield and quality of blackberry cultivars-results from a grower-cooperator trial," in Proceedings of the North American Berry Conference, North American Raspberry \& Blackberry Association, Portland, OR, USA, 2013.
[28] H.-J. Fan-Chiang and R. E. Wrolstad, “Anthocyanin pigment composition of blackberries," Journal of Food Science, vol. 70, no. 3, pp. C198-C202, 2005.

[29] T. Siriwoharn, R. E. Wrolstad, C. E. Finn, and C. B. Pereira, "Influence of cultivar, maturity, and sampling on blackberry (Rubus L. Hybrids) anthocyanins, polyphenolics, and antioxidant properties," Journal of Agricultural and Food Chemistry, vol. 52, no. 26, pp. 8021-8030, 2004.

[30] T. Siriwoharn, "Characterization of phenolics in marion and evergreen blackberries," in Food Science and Technology, p. 118, Oregon State University, Corvallis, OR, USA, 2001.

[31] P. M. Civello, G. A. Martínez, A. R. Chaves, and M. C. Añón, "Heat treatments delay ripening and postharvest decay of strawberry fruit," Journal of Agricultural and Food Chemistry, vol. 45, no. 12, pp. 4589-4594, 1997.

[32] C. L. Fisk, A. M. Silver, B. C. Strik, and Y. Zhao, "Postharvest quality of hardy kiwifruit (Actinidia arguta "Ananasnaya") associated with packaging and storage conditions," Postharvest Biology and Technology, vol. 47, no. 3, pp. 338-345, 2008.

[33] M. Joo, N. Lewandowski, R. Auras, J. Harte, and E. Almenar, "Comparative shelf life study of blackberry fruit in bio-based and petroleum-based containers under retail storage conditions," Food Chemistry, vol. 126, no. 4, pp. 1734-1740, 2011.

[34] P. Perkins-Veazie, N. Roe, J. Lasswell, and J. McFarland, "Storage life of a midseason peach held at $5^{\circ} \mathrm{C}$," HortScience, vol. 32, no. 4, pp. 598C-598, 1997.

[35] R. Wu, B. Frei, J. A. Kennedy, and Y. Zhao, "Effects of refrigerated storage and processing technologies on the bioactive compounds and antioxidant capacities of "Marion" and "evergreen" blackberries," LWT-Food Science and Technology, vol. 43, no. 8, pp. 1253-1264, 2010.

[36] M. Qian, Objective Flavor Comparison of Oregon Strawberries and Those from Other Climatic Conditions: Progress Report FY 2004-2005, Oregon Strawberry Commission, Corvallis, OR, USA, 2006.

[37] V. L. Singleton, R. Orthofer, and R. M. Lamuela-Raventós, "Analysis of total phenols and other oxidation substrates and antioxidants by means of folin-ciocalteu reagent," in Methods in Enzymology, P. Lester, Ed., pp. 152-178, Academic Press, Cambridge, MA, USA, 1999.

[38] W. Brand-Williams, M. E. Cuvelier, and C. Berset, "Use of a free radical method to evaluate antioxidant activity," LWT-Food Science and Technology, vol. 28, no. 1, pp. 25-30, 1995.

[39] M. M. Giusti and R. E. Wrolstad, "Characterization and measurement of anthocyanins by UV-visible spectroscopy," in Current Protocols in Food Analytical Chemistry, R. E. Wrolstad, Ed., pp. F1.2.1-F1.2.13, John Wiley \& Sons, Somerset, NJ, USA, 2001.

[40] G. Cao, H. M. Alessio, and R. G. Cutler, "Oxygen-radical absorbance capacity assay for antioxidants," Free Radical Biology and Medicine, vol. 14, no. 3, pp. 303-311, 1993.

[41] I. F. F. Benzie and J. J. Strain, "The ferric reducing ability of plasma (FRAP) as a measure of "antioxidant power": the FRAP assay," Analytical Biochemistry, vol. 239, no. 1, pp. 70-76, 1996.

[42] G. Cavender, M. Liu, D. Hobbs, B. Frei, B. Strik, and Y. Zhao, "Effects of different organic weed management strategies on the physicochemical, sensory, and antioxidant properties of machine-harvested blackberry fruits," Journal of Food Science, vol. 79, no. 10, pp. S2107-S2116, 2014. 
[43] J. Kidd, J. Clark, P. Fenn, and B. Smith, "Evaluation of postharvest disease resistance in blackberry cultivars," AAEs Research Series, Horticultural Studies, vol. 520, pp. 18-19, 2003.

[44] B. Williamson, B. Tudzynski, P. Tudzynski, and J. A. L. Van Kan, "Botrytis cinerea: the cause of grey mould disease," Molecular Plant Pathology, vol. 8, no. 5, pp. 561-580, 2007.

[45] P. Perkins-Veazie, J. K. Collins, and J. R. Clark, "Cultivar and maturity affect postharvest quality of fruit from erect blackberries," HortScience, vol. 31, no. 2, pp. 258-261, 1996.

[46] C. E. Finn, B. M. Yorgey, B. C. Strik, H. K. Hall, R. R. Martin, and M. Qian, "“Black diamond" thornless trailing blackberry," HortScience, vol. 40, no. 7, pp. 2175-2178, 2005.

[47] P. Perkins-Veazie, J. K. Collins, and J. R. Clark, "Shelf-life and quality of "navaho" and "shawnee" blackberry fruit stored under retail storage conditions," Journal of Food Quality, vol. 22, no. 5, pp. 535-544, 1999.

[48] J. Reyes-Carmona, G. G. Yousef, R. A. Martínez-Peniche, and M. A Lila, "Antioxidant capacity of fruit extracts of blackberry (Rubus sp.) produced in different climatic regions," Journal of Food Science, vol. 70, no. 7, pp. s497-s503, 2005.

[49] J. Duan, R. Wu, B. C. Strik, and Y. Zhao, "Effect of edible coatings on the quality of fresh blueberries (Duke and Elliott) under commercial storage conditions," Postharvest Biology and Technology, vol. 59, no. 1, pp. 71-79, 2011.

[50] L. Ali, B. Svensson, B. W. Alsanius, and M. E. Olsson, "Late season harvest and storage of Rubus berries-Major antioxidant and sugar levels," Scientia Horticulturae, vol. 129, no. 3, pp. 376-381, 2011.

[51] F. M. Woods, W. A. Dozier, R. C. Ebel et al., "Cultivar and Maturity Effects on Fruit Quality and Antioxidant Properties in Blackberry," HortScience, vol. 41, no. 4, pp. 1043-1043, 2006.

[52] T. Ozawa, T. H. Lilley, and E. Haslam, "Polyphenol interactions: astringency and the loss of astringency in ripening fruit," Phytochemistry, vol. 26, no. 11, pp. 2937-2942, 1987.

[53] C. Eaves, "Influence of preharvest sprays of calcium salts and wax on fruit quality of red raspberry," Journal of the American Society for Horticultural Science, 1972.

[54] P. Perkins-Veazie, J. R. Clark, D. J. Huber, and E. A. Baldwin, "Ripening physiology in "navaho" thornless blackberries: color, respiration, ethylene production, softening, and compositional changes," Journal of the American Society for Horticultural Science, vol. 125, no. 3, pp. 357$363,2000$.

[55] G. A. Tucker, Introduction, in Biochemistry of Fruit Ripening, G. B. Seymour, J. E. Taylor, and G. A. Tucker, Eds., Chapman \& Hall, London, UK, 1993.

[56] E. G. Mworia, T. Yoshikawa, N. Salikon et al., "Lowtemperature-modulated fruit ripening is independent of ethylene in "Sanuki Gold" kiwifruit," Journal of Experimental Botany, vol. 63, no. 2, pp. 963-971, 2012.

[57] S. Y. Wang and S.-S. Lin, "Composts as soil supplement enhanced plant growth and fruit quality of strawberry," Journal of Plant Nutrition, vol. 25, no. 10, pp. 2243-2259, 2002.

[58] D. M. Beckles, "Factors affecting the postharvest soluble solids and sugar content of tomato (Solanum lycopersicum L.) fruit," Postharvest Biology and Technology, vol. 63, no. 1, pp. 129-140, 2012.

[59] K. Skupien and J. Oszmianski, "The effect of mineral fertilization on nutritive value and biological activity of chokeberry fruit," Agricultural and Food Science, vol. 16, no. 1, pp. 46-55, 2007.
[60] L. P. Christensen, M. L. Bianchi, W. L. Peacock, and D. J. Hirschfelt, "Effect of nitrogen fertilizer timing and rate on inorganic nitrogen status, fruit composition, and yield of grapevines," American Journal of Enology and Viticulture, vol. 45 , no. 4 , pp. $377-387,1994$.

[61] L. M. Al-Kharusi, "Effect of mineral and organic fertilizers on the chemical characteristics and quality of date fruits," International Journal of Agriculture and Biology, vol. 11, pp. 290-296, 2009.

[62] H.-J. Fan-Chiang, "Anthocyanin pigment, nonvolatile acid and sugar composition of blackberries," in Food Science and Technology, p. 81, Oregon State University, Corvallis, OR, USA, 1999.

[63] E. Kafkas, M. Koşar, N. Türemiş, and K. H. C. Başer, “Analysis of sugars, organic acids and vitamin $\mathrm{C}$ contents of blackberry genotypes from Turkey," Food Chemistry, vol. 97, no. 4, pp. 732-736, 2006.

[64] R. S. Shallenberger, "Hydrogen bonding and the varying sweetness of the sugars," Journal of Food Science, vol. 28, no. 5, pp. 584-589, 1963.

[65] A. M. Fontvieille, A. Faurion, I. Helal et al., "Relative sweetness of fructose compared with sucrose in healthy and diabetic subjects," Diabetes Care, vol. 12, no. 7, pp. 481-486, 1989.

[66] I. Akhavan and R. E. Wrolstad, "Variation of sugars and acids during ripening of pears and in the production and storage of pear concentrate," Journal of Food Science, vol. 45, no. 3, pp. 499-501, 1980.

[67] B. R. Cordenunsi, M. I. Genovese, J. R. Oliveira do Nascimento, N. M. Aymoto Hassimotto, R. José dos Santos, and F. M. Lajolo, "Effects of temperature on the chemical composition and antioxidant activity of three strawberry cultivars," Food Chemistry, vol. 91, no. 1, pp. 113-121, 2005.

[68] J. A. Robertson, F. I. Meredith, B. G. Lyon, G. W. Chapman, and W. B. Sherman, "Ripening and cold storage changes in the quality characteristics of nonmelting clingstone peaches (FLA 9-20C)," Journal of Food Science, vol. 57, no. 2, pp. 462-465, 1992.

[69] R. A. Moyer, K. E. Hummer, C. E. Finn, B. Frei, and R. E. Wrolstad, "Anthocyanins, phenolics, and antioxidant capacity in diverse small fruits: vaccinium, Rubus, and ribes," Journal of Agricultural and Food Chemistry, vol. 50, no. 3, pp. 519-525, 2001.

[70] M. P. Kähkönen, J. Heinämäki, V. Ollilainen, and M. Heinonen, "Berry anthocyanins: isolation, identification and antioxidant activities," Journal of the Science of Food and Agriculture, vol. 83, no. 14, pp. 1403-1411, 2003.

[71] D. W. Ingalsbe, G. H. Carter, and A. M. Neubert, "Fruit pigment measurement, anthocyanin pigments as a maturity index for processing dark sweet cherries and purple plums," Journal of Agricultural and Food Chemistry, vol. 13, no. 6, pp. 580-584, 1965.

[72] S. Sellappan, C. C. Akoh, and G. Krewer, "Phenolic compounds and antioxidant capacity of Georgia-grown blueberries and blackberries," Journal of Agricultural and Food Chemistry, vol. 50, no. 8, pp. 2432-2438, 2002.

[73] D. C. Close and C. McArthur, "Rethinking the role of many plant phenolics-protection from photodamage not herbivores?," Oikos, vol. 99, no. 1, pp. 166-172, 2002.

[74] R. Gutser, T. Ebertseder, A. Weber, M. Schraml, and U. Schmidhalter, "Short-term and residual availability of nitrogen after long-term application of organic fertilizers on 
arable land," Journal of Plant Nutrition and Soil Science, vol. 168, no. 4, pp. 439-446, 2005.

[75] A. R. Reddy, K. V. Chaitanya, and M. Vivekanandan, "Drought-induced responses of photosynthesis and antioxidant metabolism in higher plants," Journal of Plant Physiology, vol. 161, no. 11, pp. 1189-1202, 2004.

[76] J. Dat, S. Vandenabeele, E. Vranová, M. Van Montagu, D. Inzé, and F. Van Breusegem, "Dual action of the active oxygen species during plant stress responses," Cellular and Molecular Life Sciences (CMLS), vol. 57, no. 5, pp. 779-795, 2000.

[77] J. P. Bryant, F. S. Chapin, P. B. Reichardt, and T. P. Clausen, "Response of winter chemical defense in Alaska paper birch and green alder to manipulation of plant carbon/nutrient balance," Oecologia, vol. 72, no. 4, pp. 510-514, 1987.

[78] G. R. Iason, S. E. Hartley, and A. J. Duncan, "Chemical composition of Calluna vulgaris (Ericaceae): do responses to fertilizer vary with phenological stage?," Biochemical Systematics and Ecology, vol. 21, no. 3, pp. 315-321, 1993.

[79] W. Kalt, C. F. Forney, A. Martin, and R. L. Prior, "Antioxidant capacity, vitamin C, phenolics, and anthocyanins after fresh storage of small fruits," Journal of Agricultural and Food Chemistry, vol. 47, no. 11, pp. 4638-4644, 1999.

[80] J. Pérez-Ilzarbe, T. Hernández, I. Estrella, and M. Vendrell, "Cold storage of apples (cv. Granny Smith) and changes in phenolic compounds," Zeitschrift für Lebensmitteluntersuchung und-Forschung A, vol. 204, no. 1, pp. 52-55, 1997.

[81] R. M. Rivero, J. M. Ruiz, P. C. García, L. R. López-Lefebre, E. Sánchez, and L. Romero, "Resistance to cold and heat stress: accumulation of phenolic compounds in tomato and watermelon plants," Plant Science, vol. 160, no. 2, pp. 315-321, 2001.

[82] Z. Zhao, W. Jiang, J. Cao, Y. Zhao, and Y. Gu, "Effect of coldshock treatment on chilling injury in mango (Mangifera indica L. cv. "Wacheng") fruit," Journal of the Science of Food and Agriculture, vol. 86, no. 14, pp. 2458-2462, 2006. 


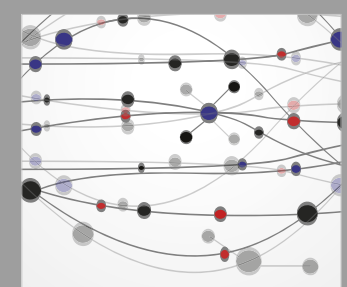

The Scientific World Journal
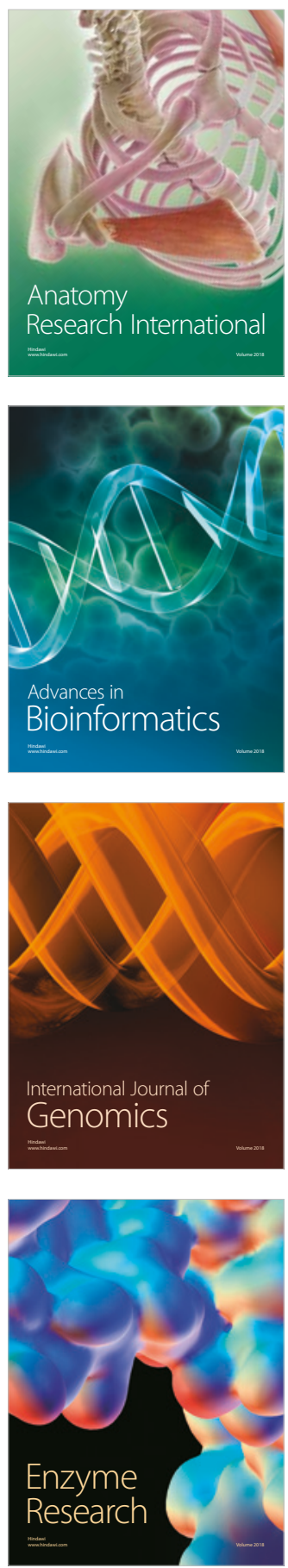
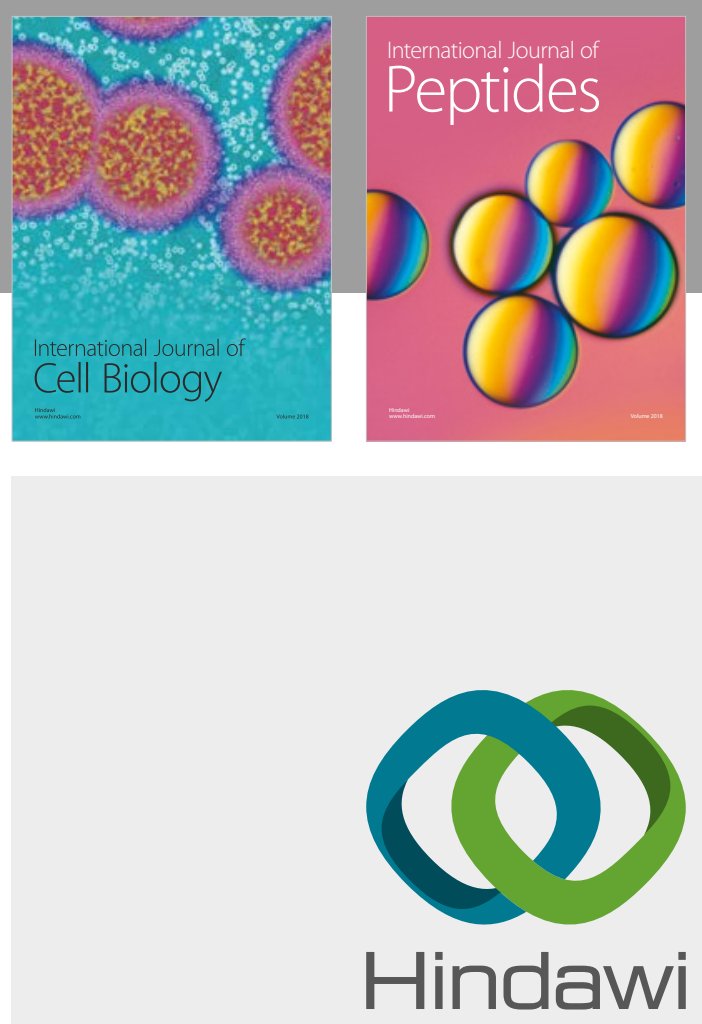

Submit your manuscripts at

www.hindawi.com
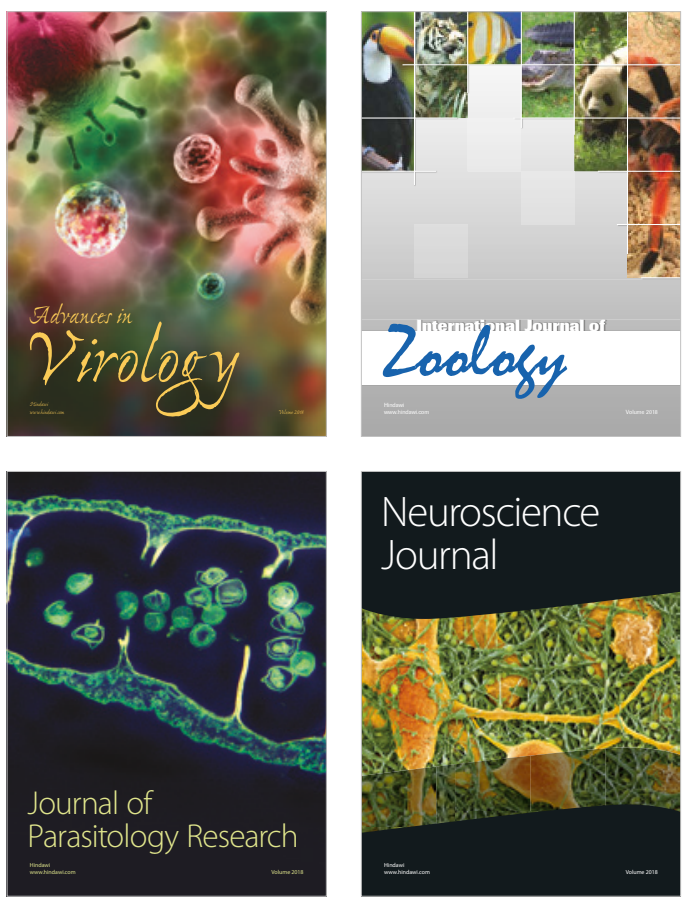
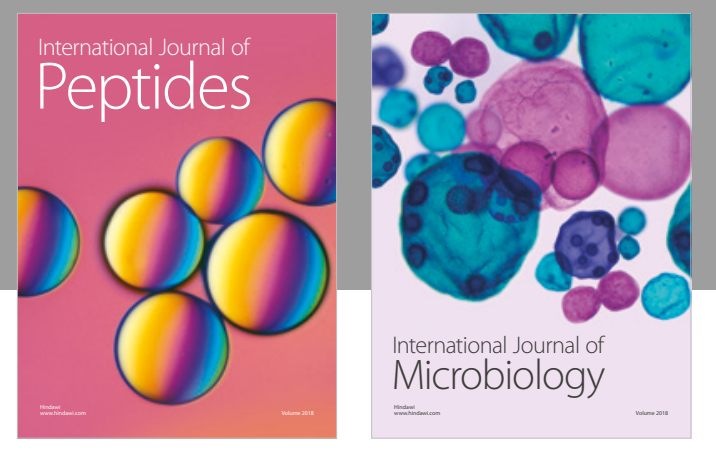

nternational Journal of Microbiology
Journal of
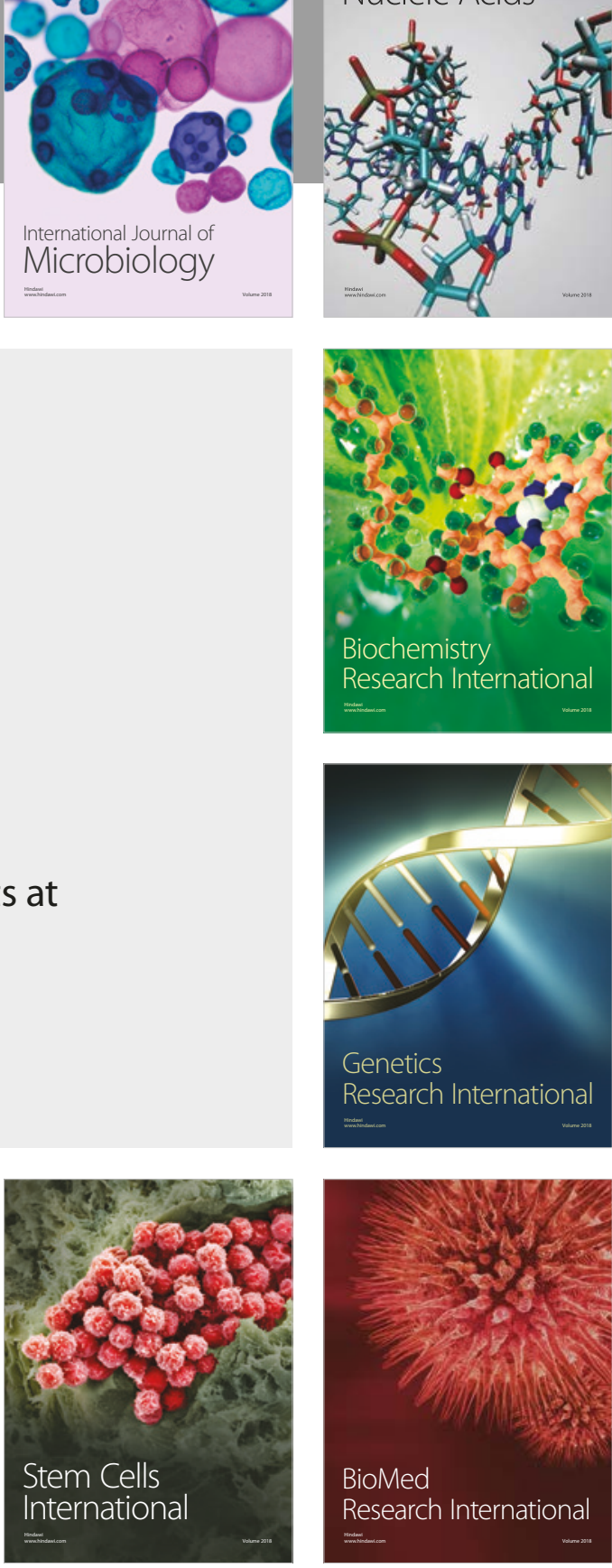
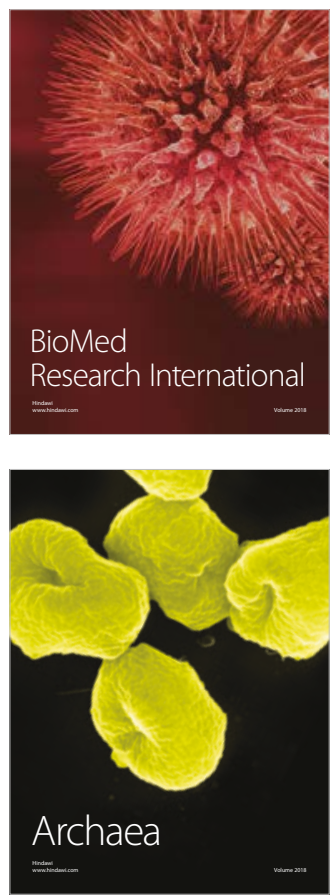